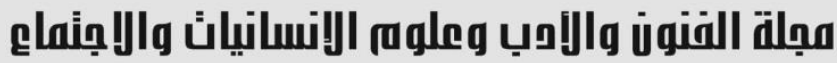

Journal of Arts, Literature, Humanities and Social Sciences www.jalhss.com

\section{الماسريالية في اعمال الفنان سيروان باران}

قزيلا عدنان حسن التشكيلي - كلية الفنون الجميلة_ جامعة صلاح الدين-اربيلـ كردستان العراق الايميل: juleadnan@gmail.com

م.د. تانيا عبد البصير محمد

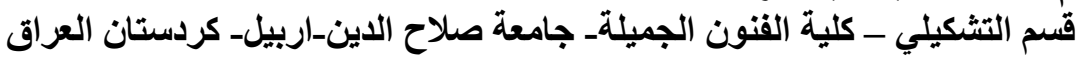
tanyaqais@gmail.com الايميل

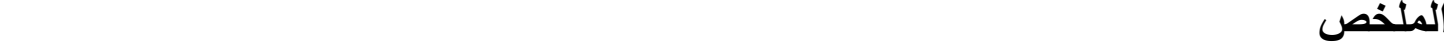

للحركة السريالية في الفن التشكيلي حضور بارز في نشاطات معظم الفنانين وفي مختلف انحاء العالم، وكان لها

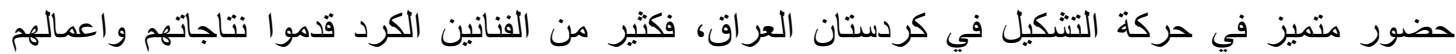

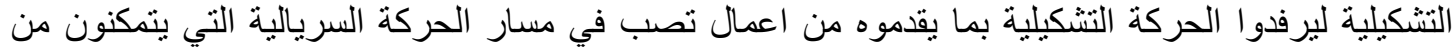

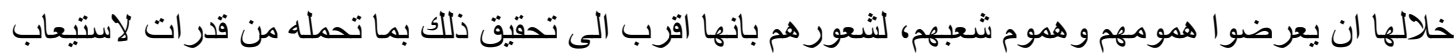

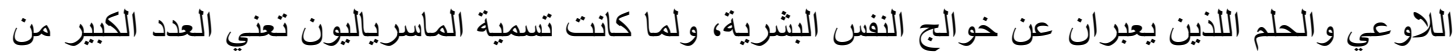

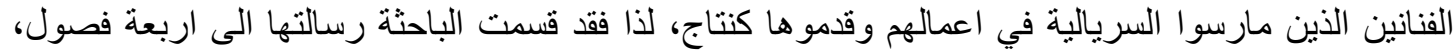

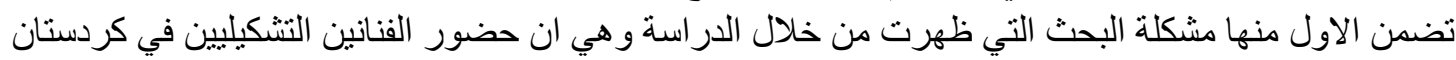

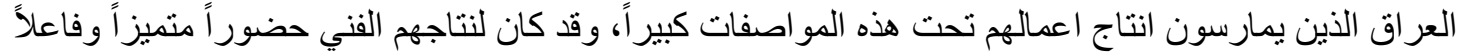

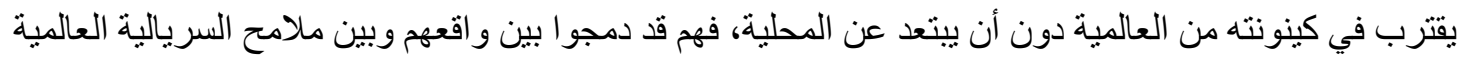

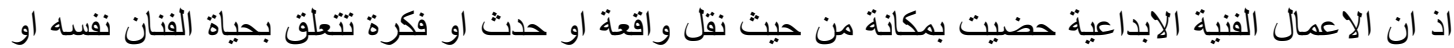
تمثل مشاهد عامة ربما تعكس قضايا تتعلق بالمنظومة المجتمعية وعليه فان مشكلة البحث تتركز في الاسئلة

1 -هل شكلت تقنية الماسريالية حركة جديدة بين الفنانين الكورد المعاصرين؟

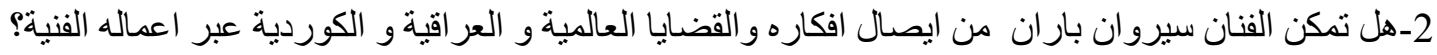

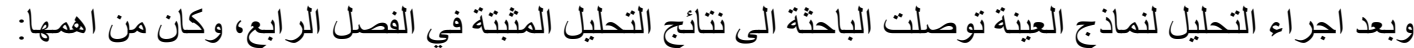

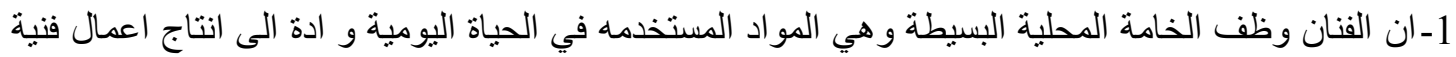

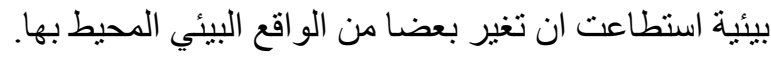

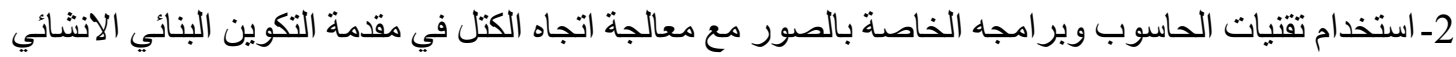
وتقديمها كاعمال ماسريالية. 3- استخدام تقنية الكو لاج و التصوير الفوتوغر افي و لصق الصفالئ اعلانات الجر ائد و المجلات في عمل فني. 4- عبر الفنان سيروان بار ان عن القضايا البيئية و الاجتماعية و السياسيه عن طريق اعماله الفنيه. 


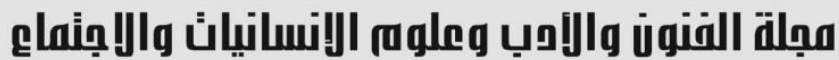 \\ Journal of Arts, Literature, Humanities and Social Sciences \\ www.jalhss.com

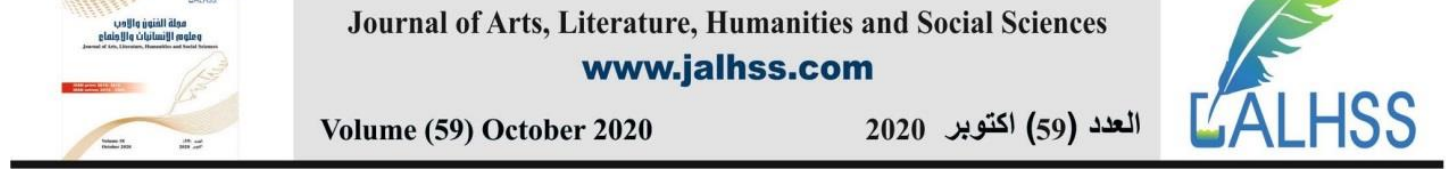 \\ Massurrealism in the Work of the Artist Serwan Baran
}

\author{
Julie Adnan Hassan \\ Plastic Arts Department - College of Fine Arts - University of Salahaddin - Iraqi Kurdistan \\ Email:juleadnan@gmail.com \\ Dr. Tania Abdel Baseer Mohamed \\ Plastic Arts Department - College of Fine Arts - University of Salahaddin - Iraqi Kurdistan \\ Email: tanyaqais@gmail.com
}

\begin{abstract}
The surrealist movement in plastic art has a prominent presence in the activities of most artists and in various parts of the world, and it had a distinct presence in the formation movement in Iraqi Kurdistan. Many Kurdish artists presented their products and plastic works in order to supply the plastic movement with the works they present that feed into the path of the surrealist movement that they are able to During it, they present their concerns and the concerns of their people, because they feel that it is closer to achieving this with the capabilities it carries to absorb the unconscious and the dream that express the outside of the human psyche, and since the name Massurealism means the large number of artists who practiced surrealism in their works and presented it as a product. Four seasons, The first of them included the research problem that emerged through the study, which is that the presence of plastic artists in Iraqi Kurdistan who practice producing their works under these specifications is great, and their artistic productions had a distinguished and effective presence that approached the global being without moving away from the local, they merged between Their reality is among the features of global surrealism, as the creative artworks have gained a place in terms of conveying an event, event, or idea related to the artist's life himself or representing public scenes that may reflect issues related to the societal system. Therefore, the research problem is concentrated in the following questions:

1-Did the Massuriyalist technique constitute a new movement among contemporary Kurdish artists?

2- Has the artist Serwan Baran been able to communicate his ideas and global, Iraqi and Kurdish issues through his artistic works?

After conducting the analysis of the sample forms, the researcher came to the results of the analysis proven in the fourth chapter, and the most important of them were:

1 - The artist employed the simple local material, which is the materials used in daily life and led to the production of environmental artworks that were able to change some of the surrounding environmental reality.

2- The use of computer technologies and programs for pictures with addressing the direction of blocks in the introduction to the structural formation and presenting them as Masurian works.

3-Using the technique of collage and photography and pasting newspaper and magazine advertisements into a work of art.

4- The artist, Sirwan Baran, expressed the environmental, social and political issues through his artistic works.
\end{abstract}

Keywords: Massurrealism, Serwan Baran, contemporary art, Kurdish artists. 


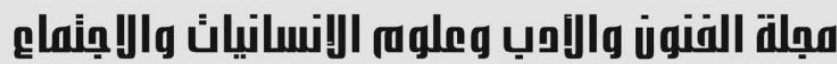

\author{
Journal of Arts, Literature, Humanities and Social Sciences \\ www.jalhss.com
}

\section{الفصل الاول

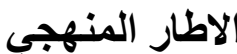

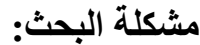

تحو لات كثيرة طر أت على مسيرة الفن العالمي و انعكس ذللك على الفن العر اقي عموما، وقد تبلورت مسيرة الفن الفي

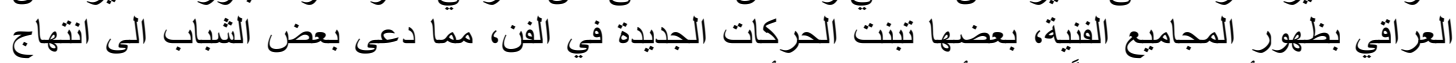

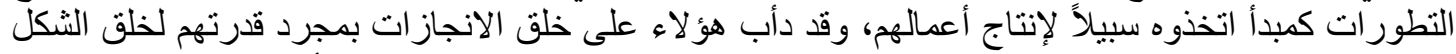

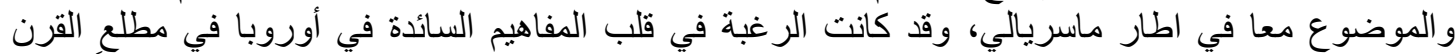

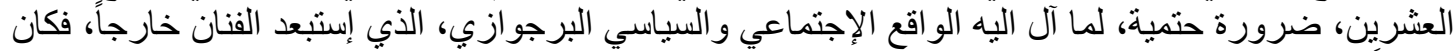

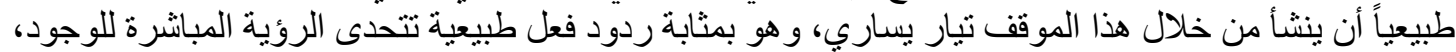

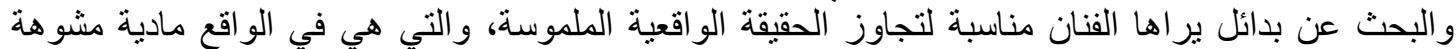

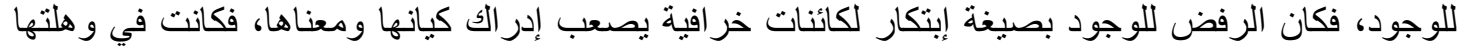

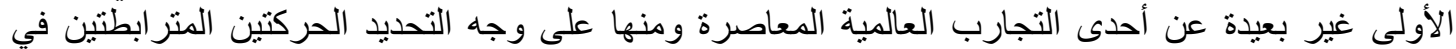

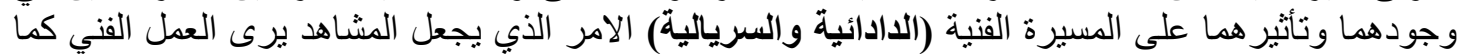

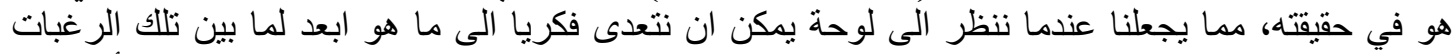

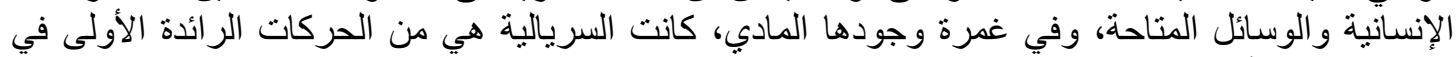

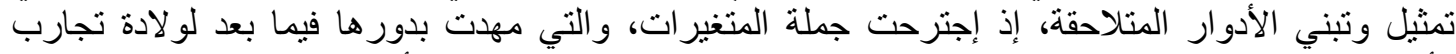

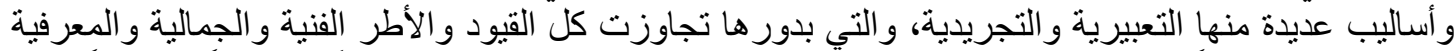

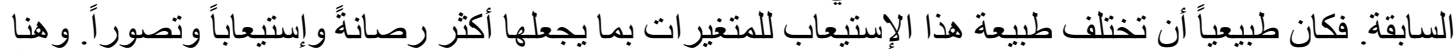

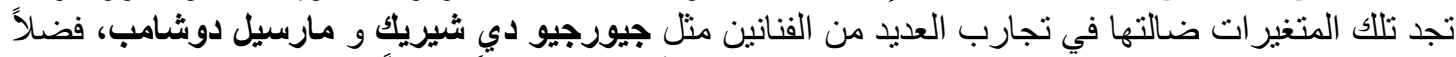

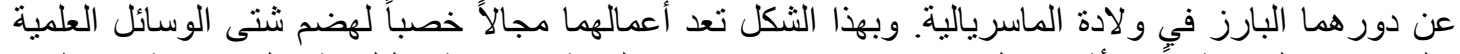

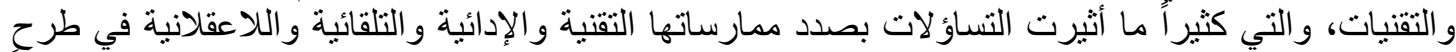

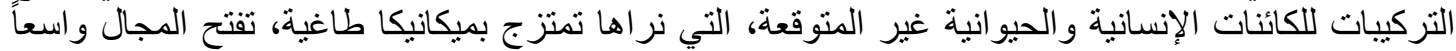
لإستقر اء وبحث سماتها الإسلو بية.

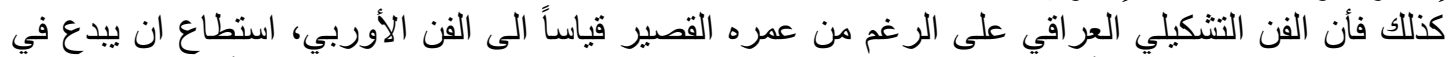

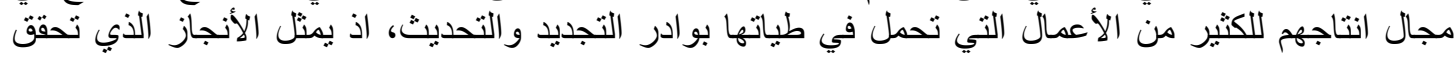

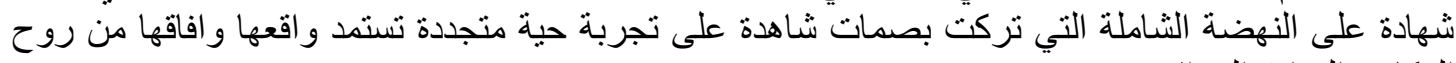

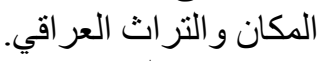
احد هؤلاء الثباب هو الفنان سيروان باران الذي الذي استطاع ان يضع بصمته بوضوح في تيار الحركة الفنية

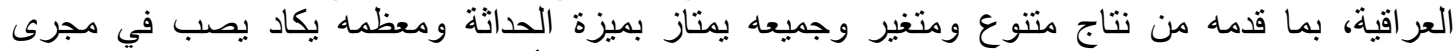

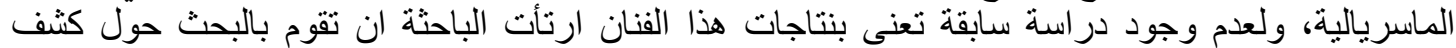
الملامح الماسريالية في اعماله.

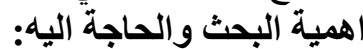

1. قدم الفنان سيروان باران فناً حديثاً ذو خصوصية، وبما انها لم تجر دراسة علمية مستقلة تستكثف لنا

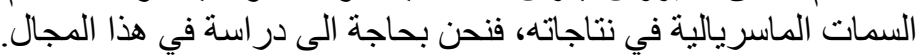

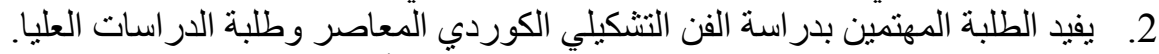

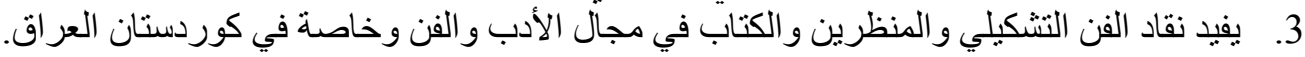

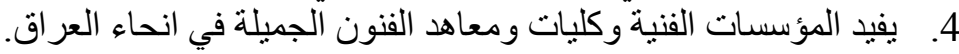

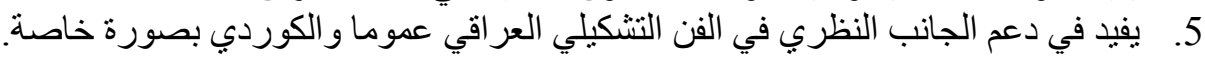
6. رفد المكتبة الفنية بما يمكن ان يجعلها الشمل في علميا.

يهدف البحثث البى (الكثف عن الماسريالية في اعمال الفنان سيروان باران).

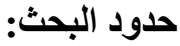
يتحدد البحث بعموم نتاجات الفنان سيروان بار ان. 


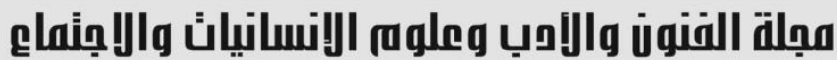

Journal of Arts, Literature, Humanities and Social Sciences

www.jalhss.com

\section{الفصل الثاني \\ الإطار النظري}

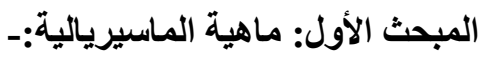

مفهوم الماسيريالية:

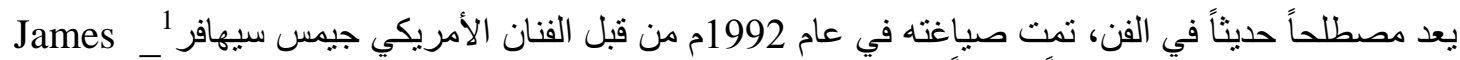
seehafer

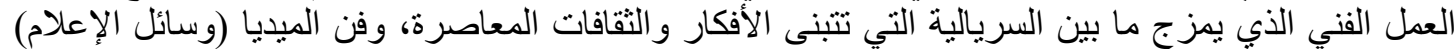

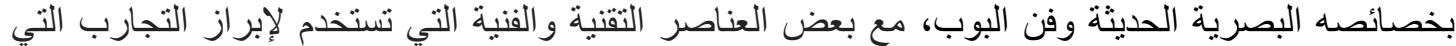

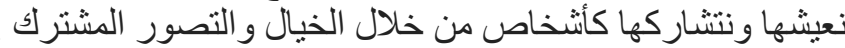

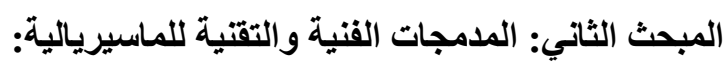

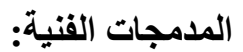

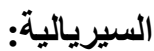

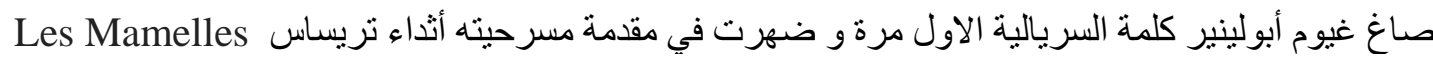

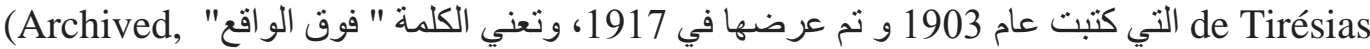
2010)

نشأت المدرسة السيريالية الفنية في فرنسا، وازدهرت في العقدين الثاني و الثالث من القرن العشرين، وتميزت العبرت

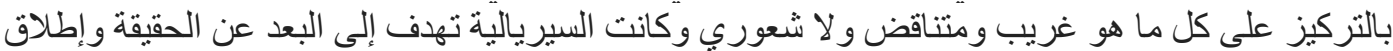

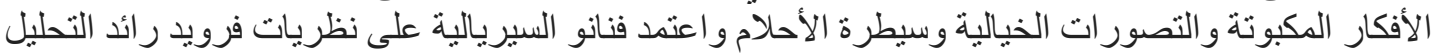

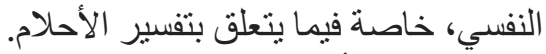

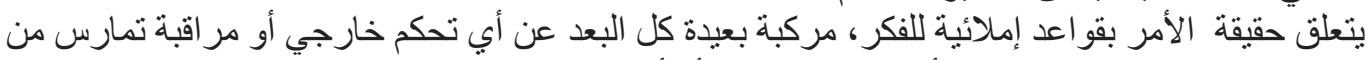

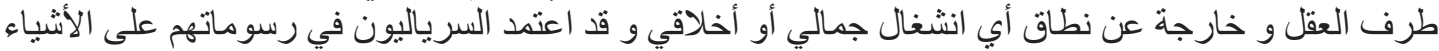

الو اقعية في استخدامها كرموز للتعبير عن أحلامهم و الارتقاء بالأشكال الطبيعية إلى ما فوق التئ الو اقع المرئي. (2016،Bernard Juohanthan) كانت الحرب العالمية الأولى مبعثرة للكتاب و الفنانين الذين كانو ا يقيمون في باريس ، وفي هذه الألثاء الكاء ، أصبح

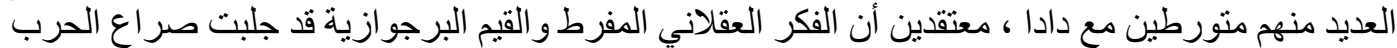

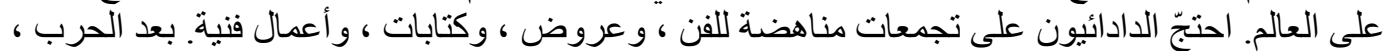
عندما عادوا إلى باريس ، استمرت النيون على أنشطة دادا.

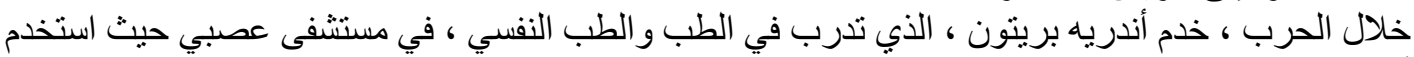

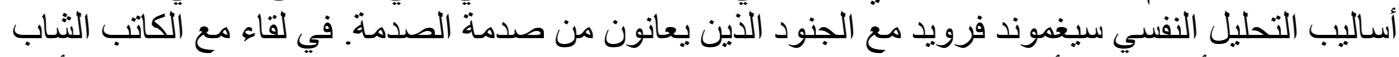

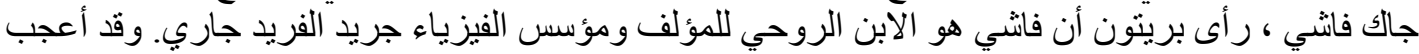

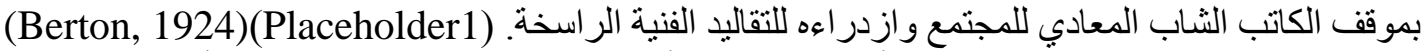

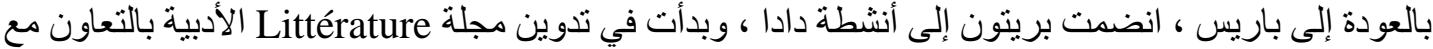

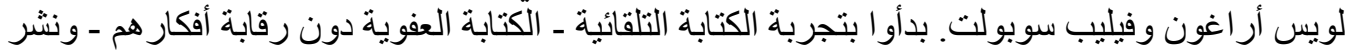
الكتابات ، وكذللك حسابات الأحلام ، في المجلة.

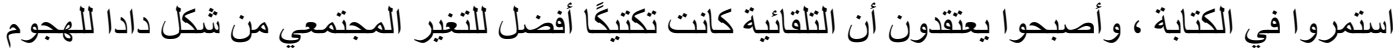

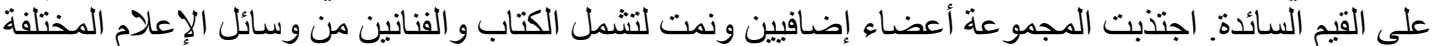

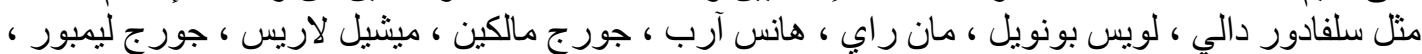

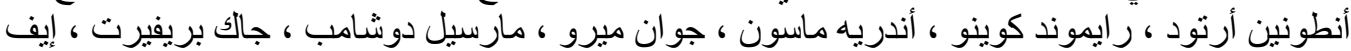

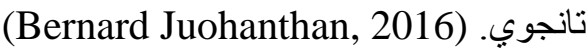




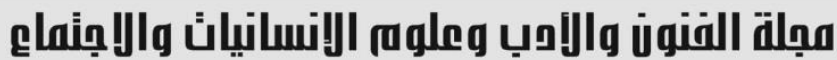

Journal of Arts, Literature, Humanities and Social Sciences
www.jalhss.com
$=\quad 2020$

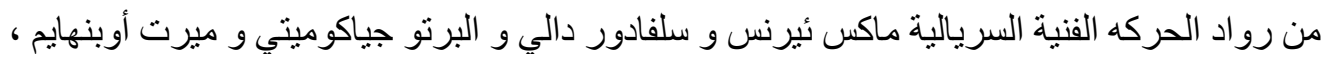

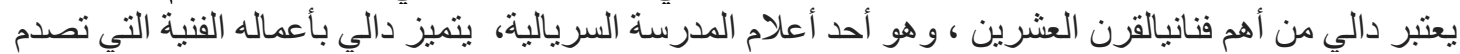

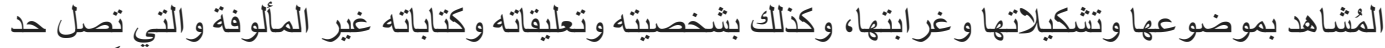

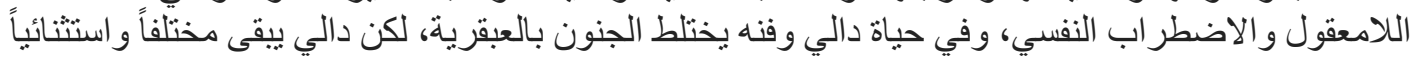

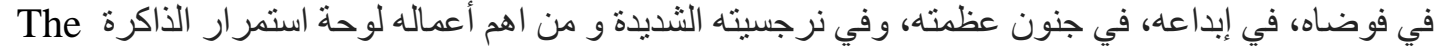
Persistence of Memory

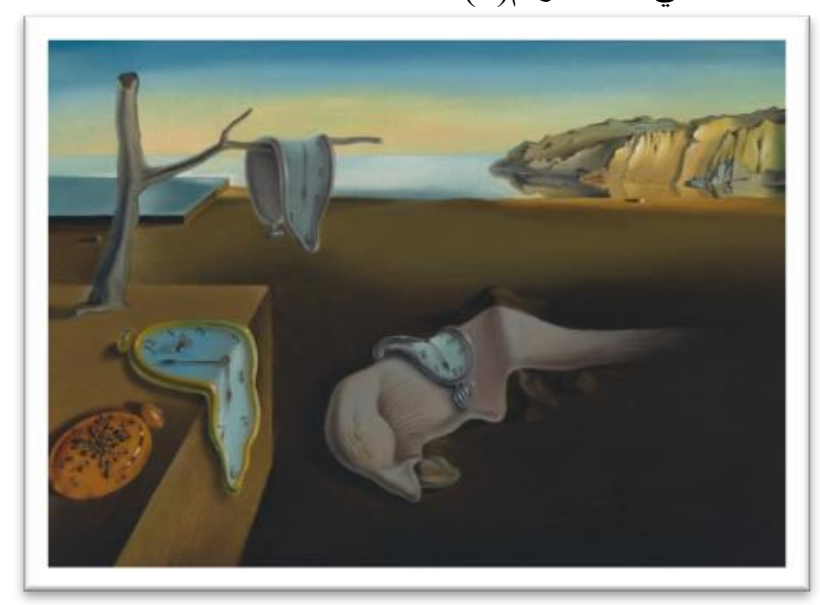

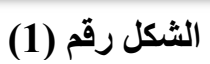

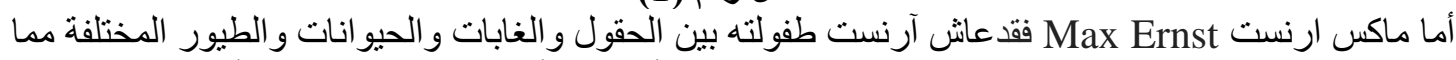

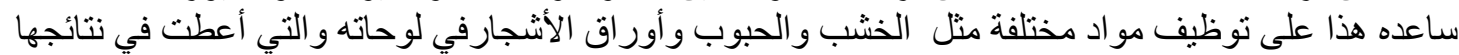

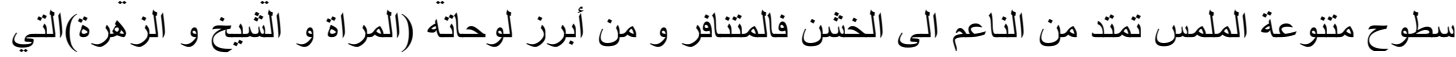
رسمها سنة 1923 كما في الثكل رقم (2).

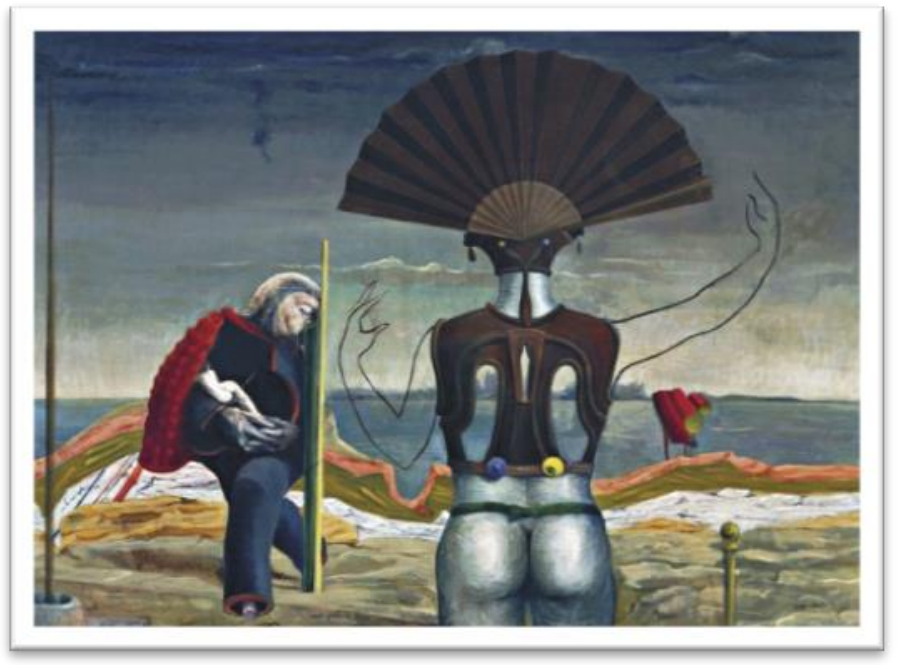

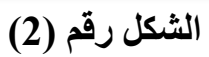

مع تطور السرياليين لفلسفتهم ، اعتقدوا أن السريالية ستدافع عن الفكرة القائلة بأن التعبيرات العادئ العادية والتعبيرية

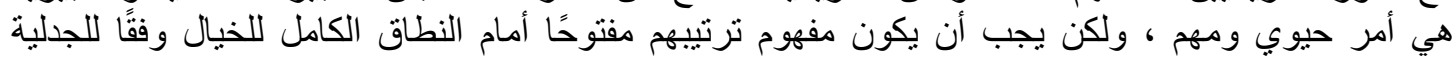

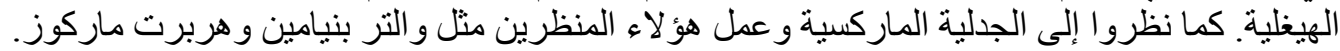

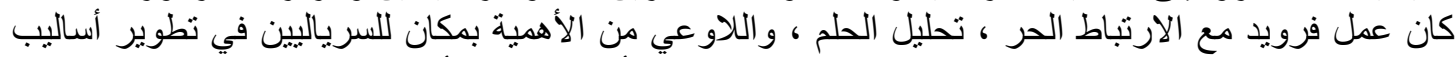

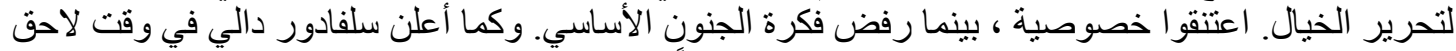
، "لا يوجد سوى فارق واحد بيني وبين مجنون. لست غاضباً." (Archived, 2010) 


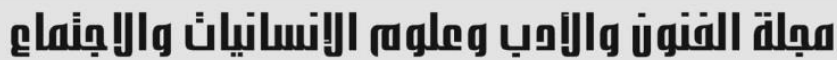

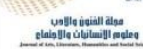

Journal of Arts, Literature, Humanities and Social Sciences

www.jalhss.com

Volume (59) October 2020

العدد (59) اكتوبر 2020

بجانب استخدام تحليل الأحلام ، شددوا على أنه "يمكن الجمع بين داخل الإطار نفسه ، عناصر لا توجد عادة معًا

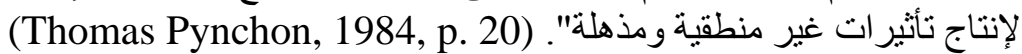

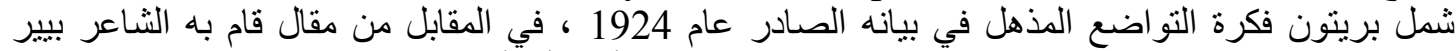

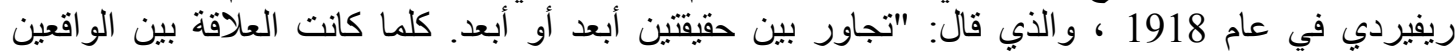

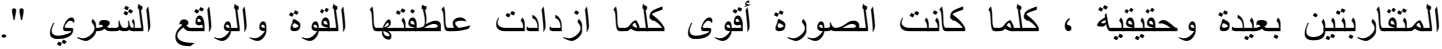

(Archived, 2010)

تهدف المجمو عة إلى إحداث ثورة في التجربة الإنسانية ، في جو انبها الثخصية و الثقافية والاجتماعية و السياسية.

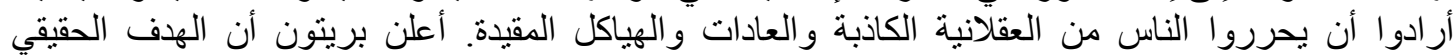

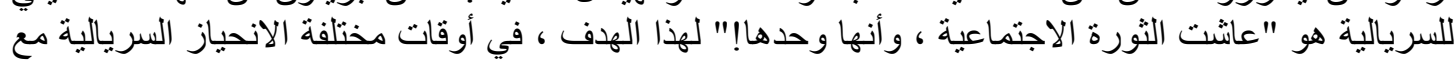

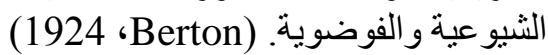
في عام 1924 أعلن فصيلان سرياليان فلسفتهما في بيانين سرياليين منفصلين، في نفس العام تم تأسيس مكتب

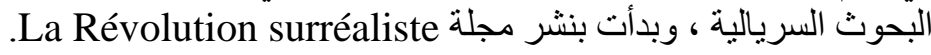

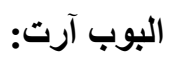

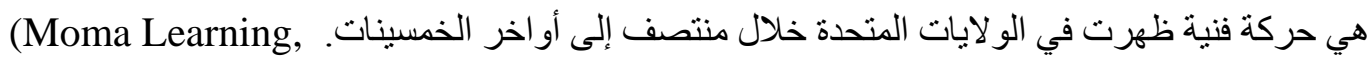

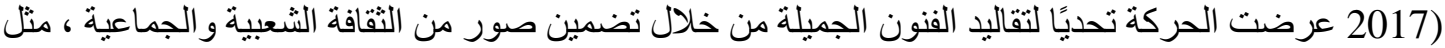

الإعلانات و الكتب المصورة و الأشياء الثقافية الدنيوية. أحد أهدافه هو استخدام صور الثينة الثقافة الثعبية (في مقابل

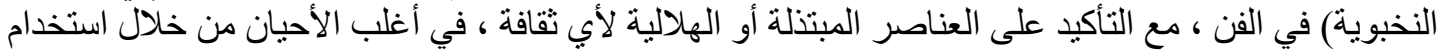

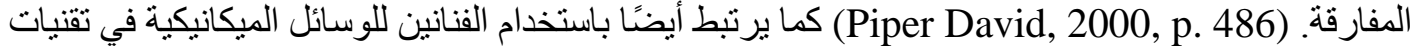

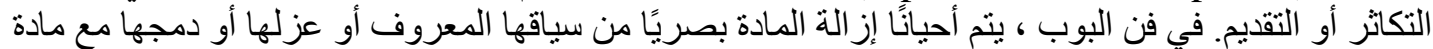

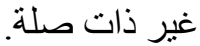
ومن بين الفنانين الأو ائل الذين شكلو ا حركة الفن الثعبي كان إدواردو باولوزي ورئن ورينشارد هاميلتون في بريطانيا

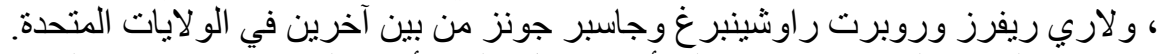

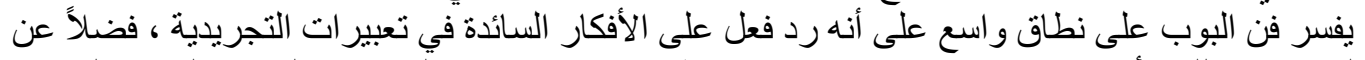

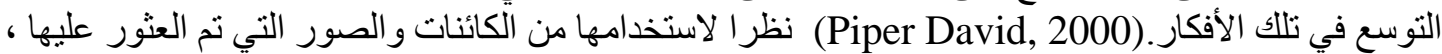

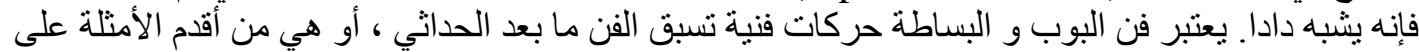

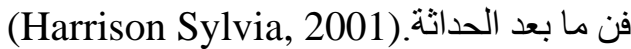

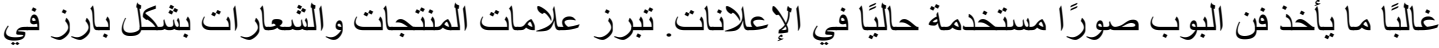

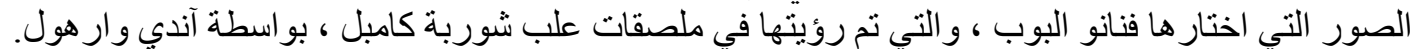

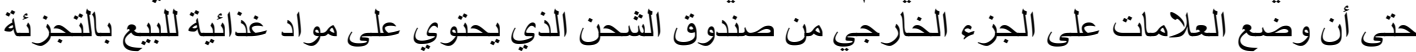

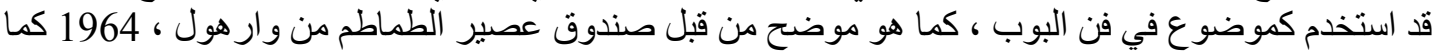

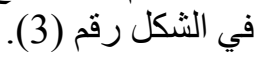

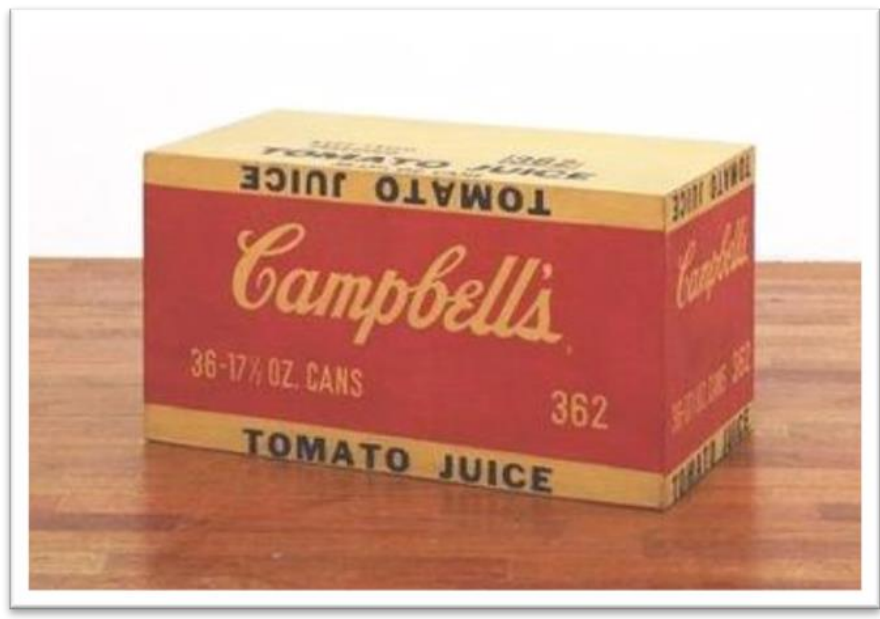

(3) (الشكل رقم 


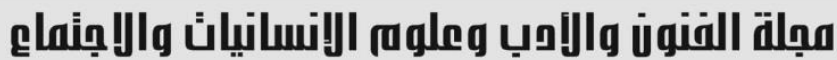

Journal of Arts, Literature, Humanities and Social Sciences www.jalhss.com

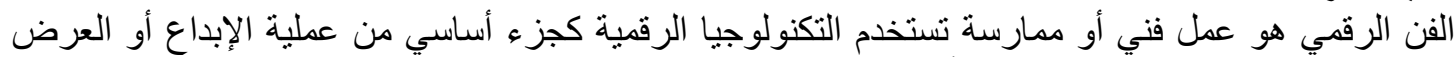

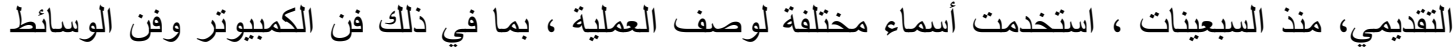

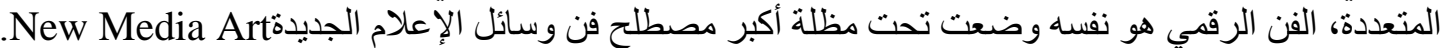
(Christian Paul , 2006, pp. 7-8)

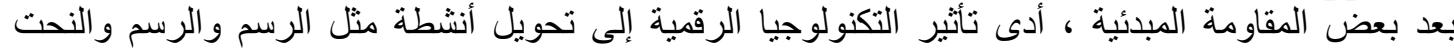

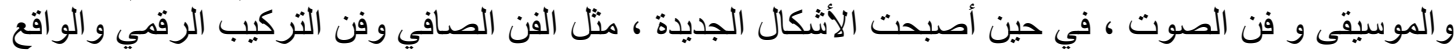

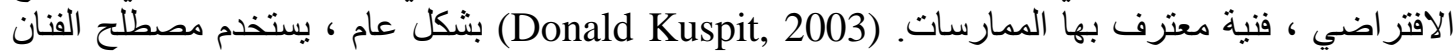

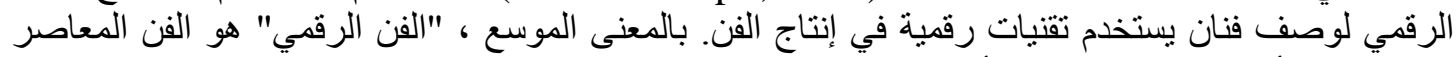

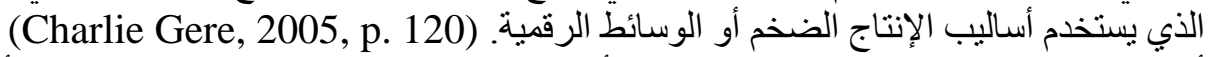

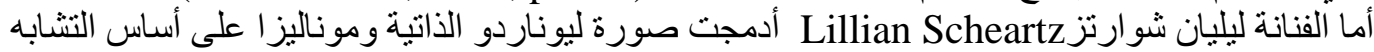

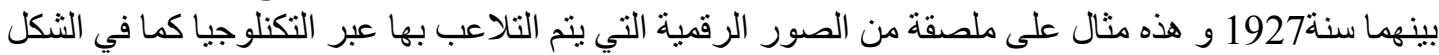
رقم (4)

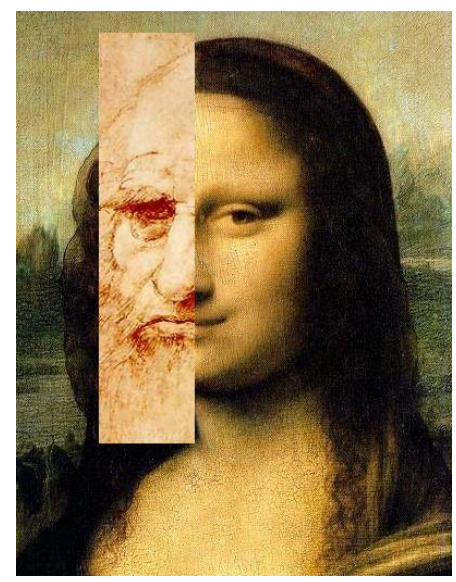

(4) (الشكل رقم

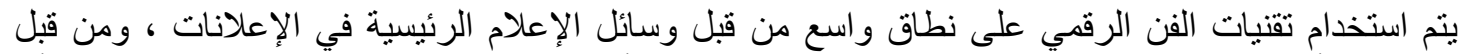

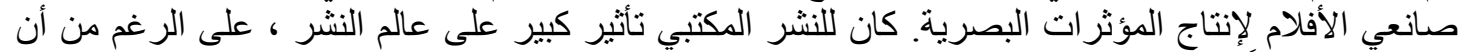

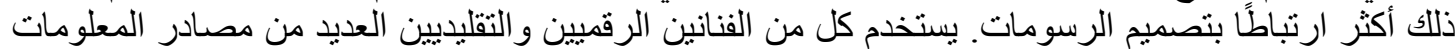

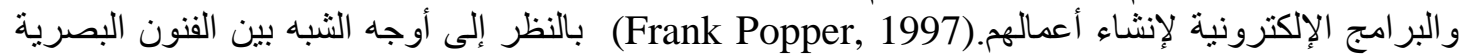

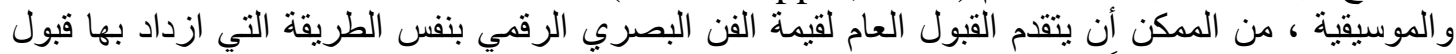

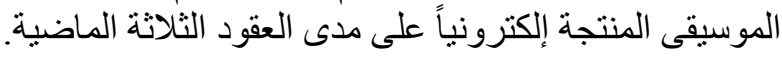

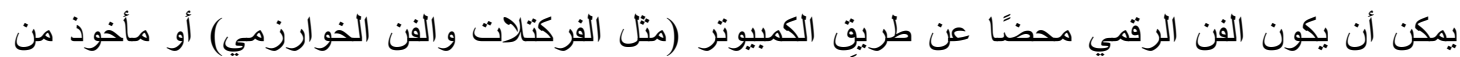

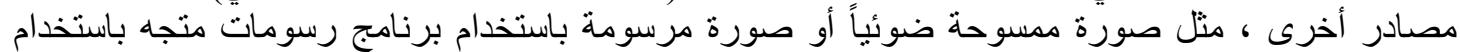

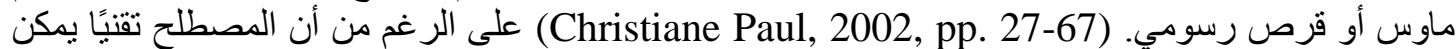

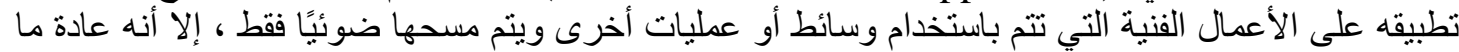

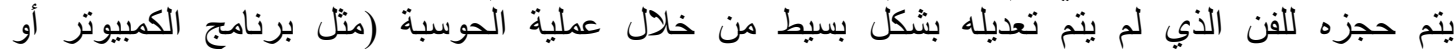

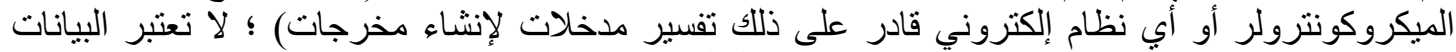

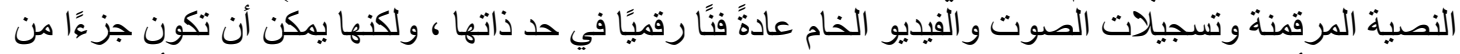

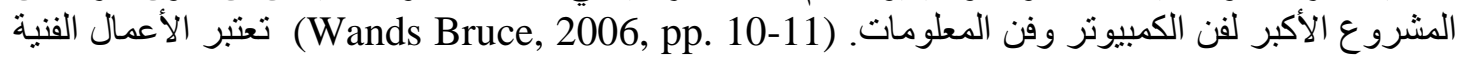

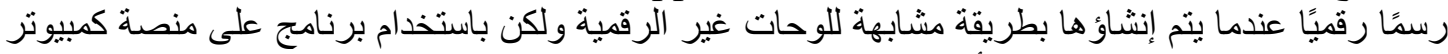

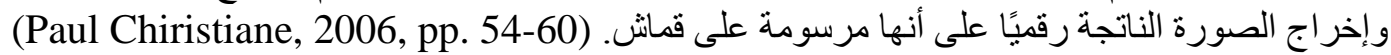




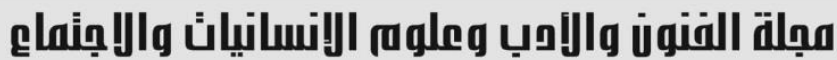

Journal of Arts, Literature, Humanities and Social Sciences

www.jalhss.com

أنشأ آندي وار هول فنًا رقميًا باستخدام Commodore Amiga حيث تم تقديم الكمبيوتر بشكل علني في مركز

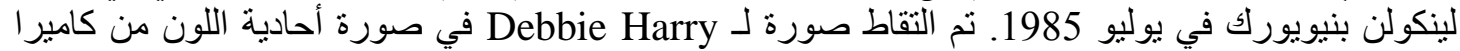

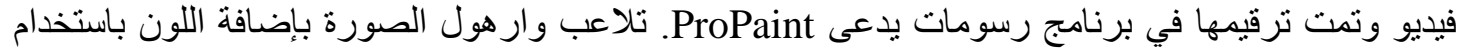

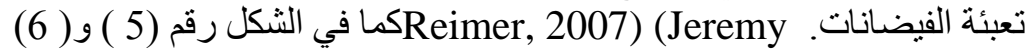

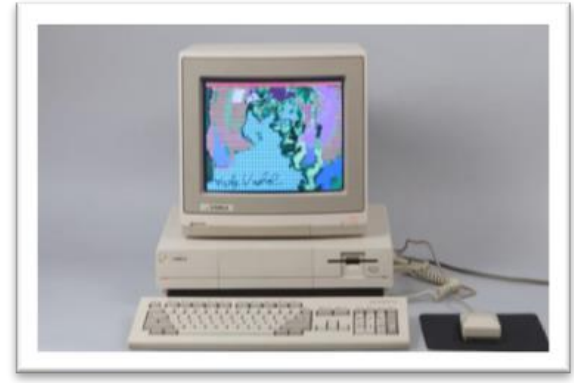

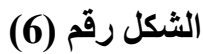

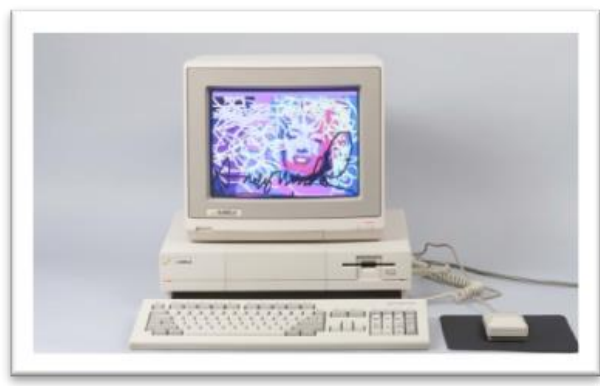

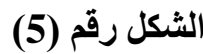

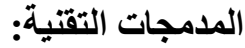

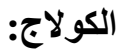

بدأ فن اللصق (Collage Art) بالمعنى الحداثي مع الرسامين المكسيكيين جور ج بر الك و بابلو بيكاسو ، كان

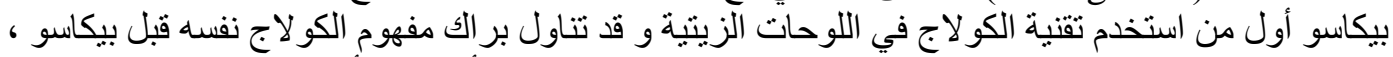

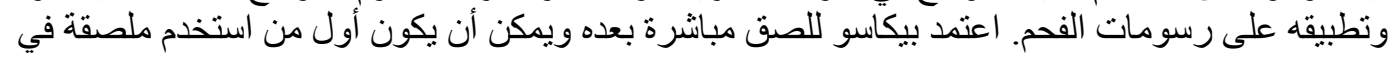

اللوحات الزيتنة.

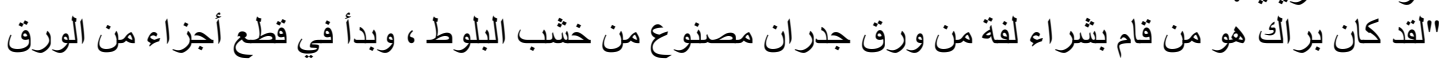

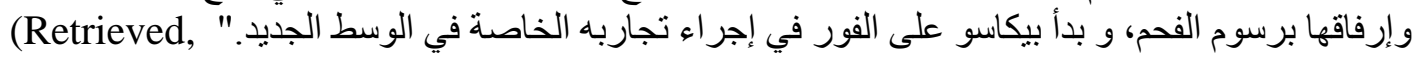
2008)

اذ تعد هذا اولى محاو لات اللصق مع الرسم بالفحم و قلم الرصاص كما في الثكل رقم (7 )

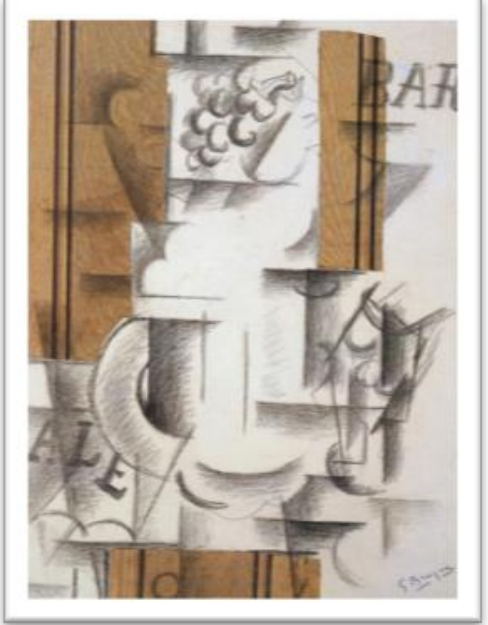

(7) (الثكل رقم

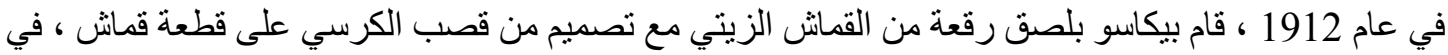

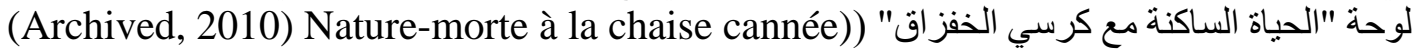

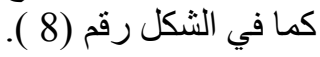



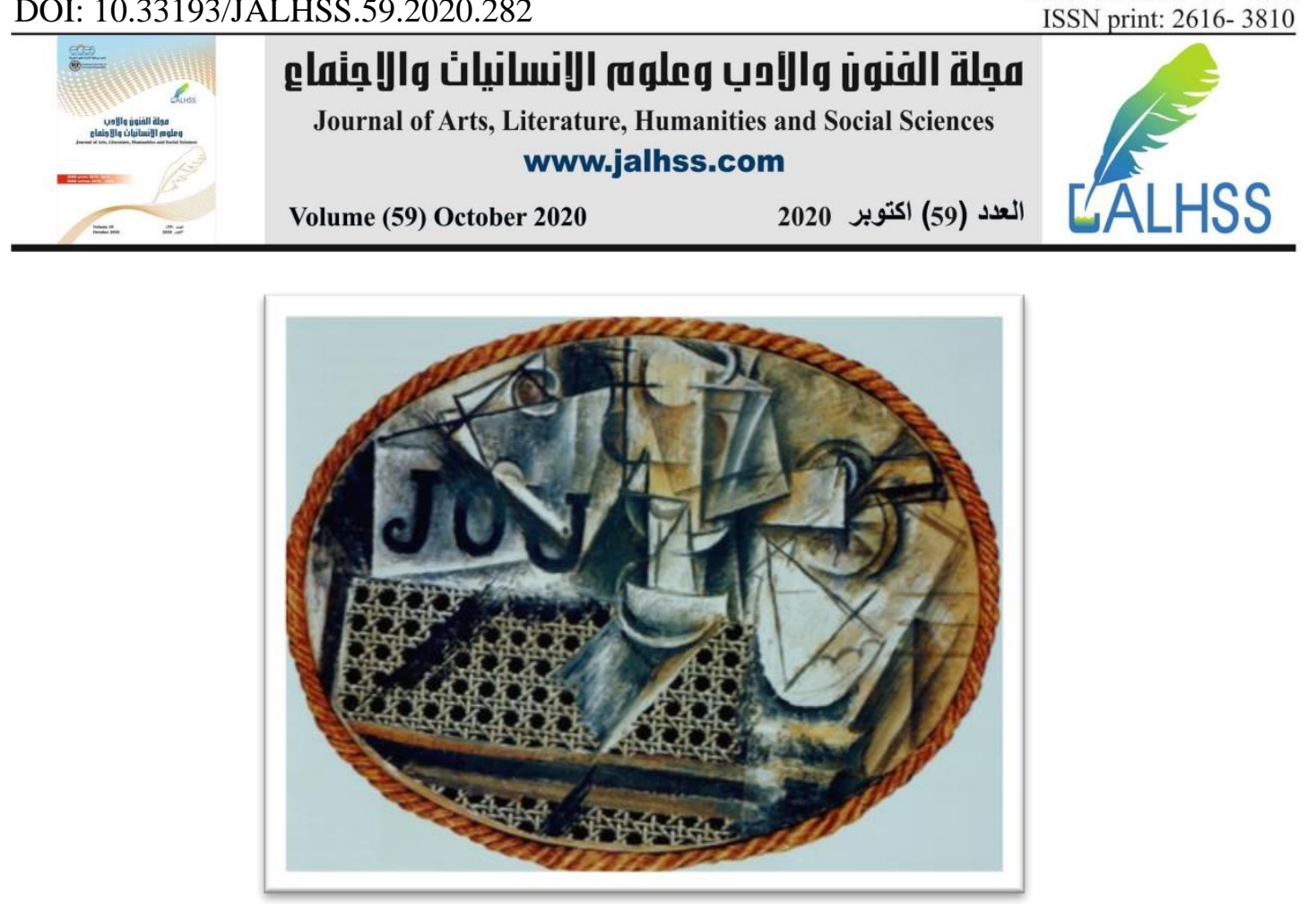

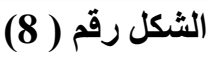

استخدم الفنانون السرياليون استخدامًا واسعًا للفن التصويري، Cubomania وهو كو لاج مصنو ع من خلال قطع

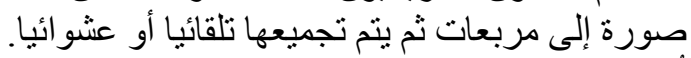

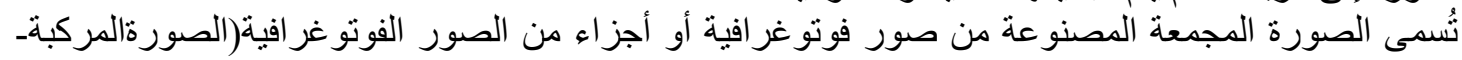
مe composite picture

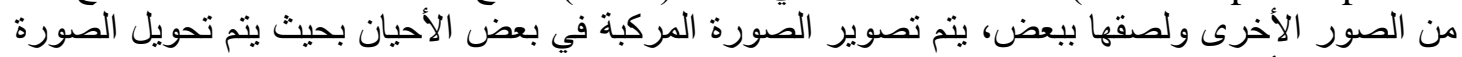

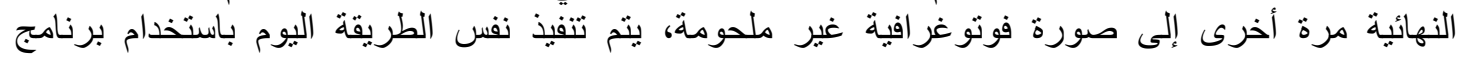

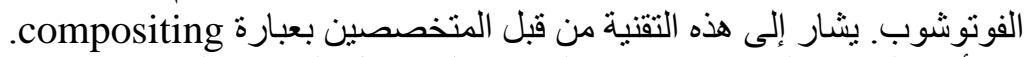

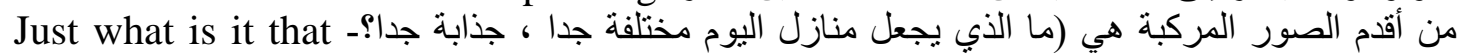
Richard اللذي رسمه(ريتشارد هاميلتون- (makes today's homes so different, so appealing?

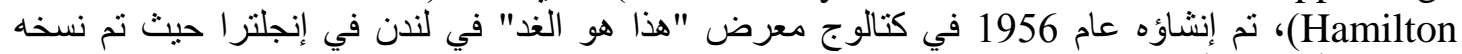
باللونين الأسود و الأبيض، بالإضافة إلى ذلك ، تم استخدام القطعة في ملصقات للمعرض. (Archived, 2010)

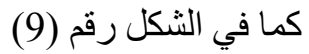

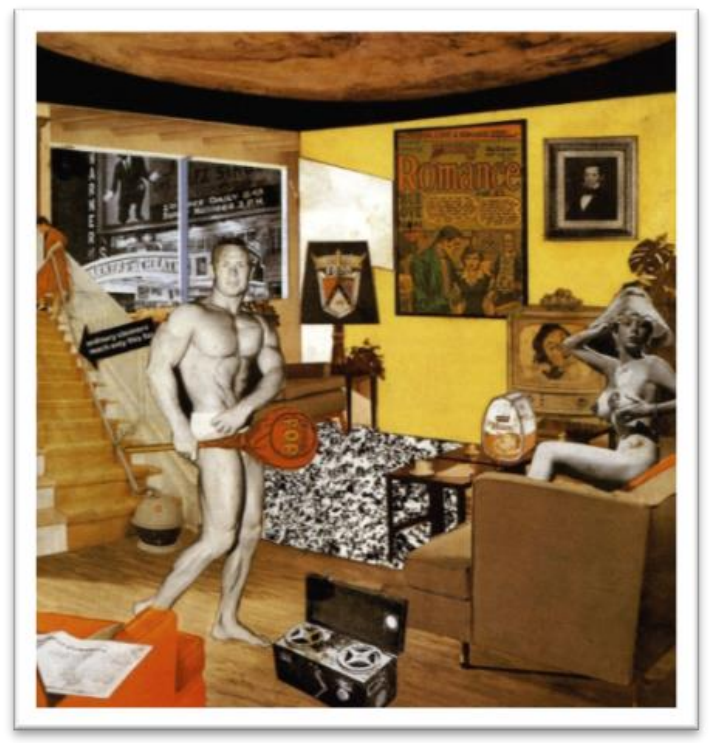

(9) (الشكل رقم 


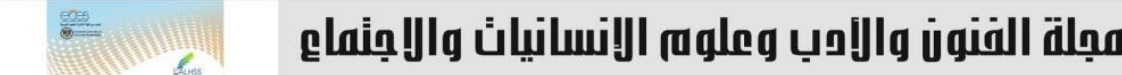 \\ Journal of Arts, Literature, Humanities and Social Sciences

\begin{tabular}{|c|c|c|c|}
\hline & wwn & & \\
\hline & Volume (59) October 2020 & العدد (59) اكتوبر 2020 & \\
\hline
\end{tabular} \\ التصوير الفوتغرافي}

أول تصوير دائم كان صورة تم إنتاجها عام 1822 من قبل المخترع الفرنسي نيكفور نييبس ، ولكن تم تدمير ها

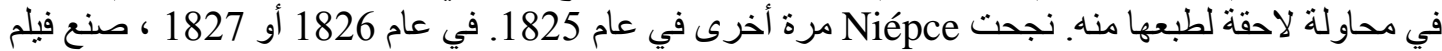

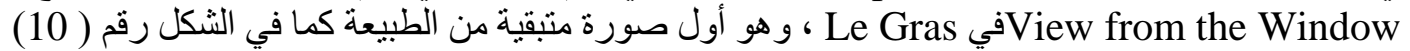

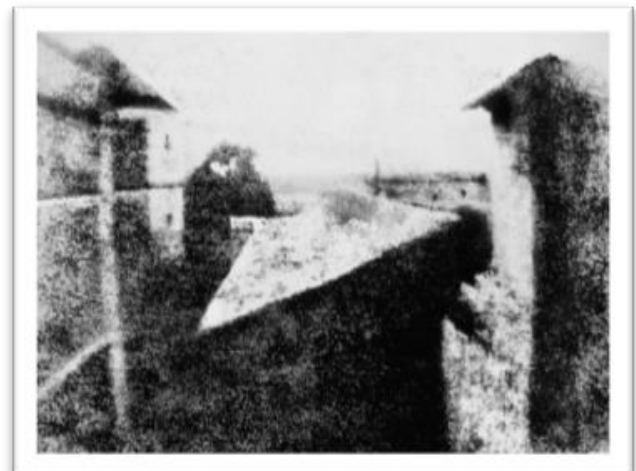

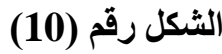

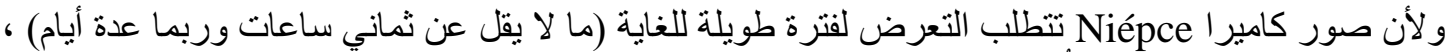

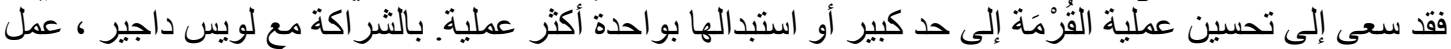

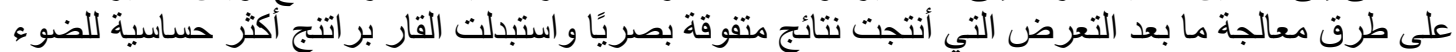

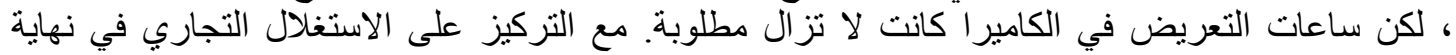
المطاف ، اختار الشركاء السرية التامة الترائ.

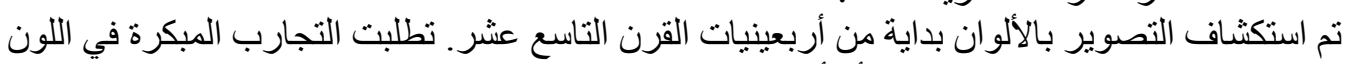

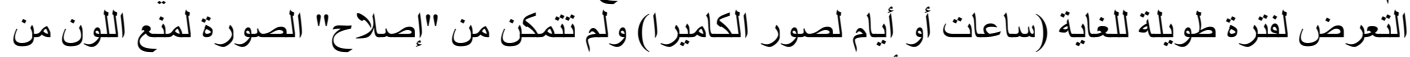

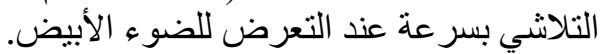

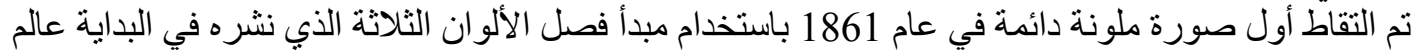
الفيزياء الاسكتلندي جيمس كليرك ماكسويل في عام 1855. [29] [30] كما في الثكل رقم (11)

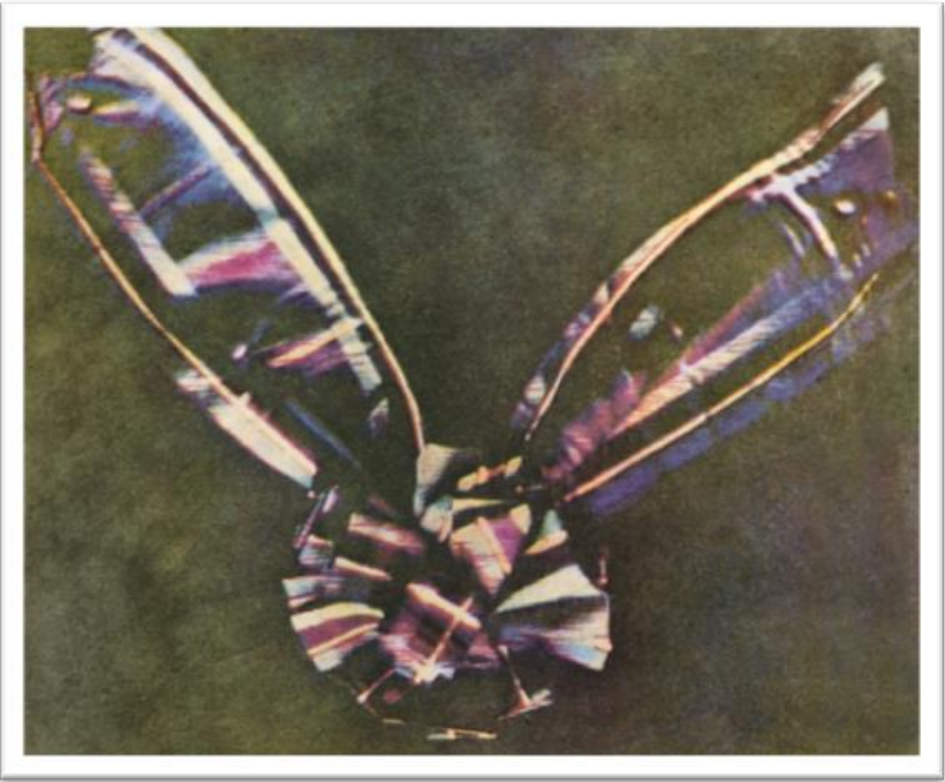

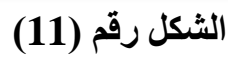




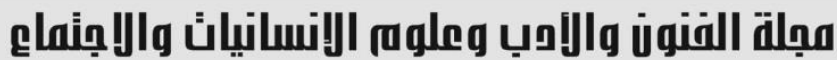

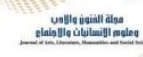

Journal of Arts, Literature, Humanities and Social Sciences

www.jalhss.com

أساس كل العمليات العملية للون ، كانت فكرة ماكسويل هي أخذ ثلاث صور منفصلة بالأبيض و الأسود من خلال

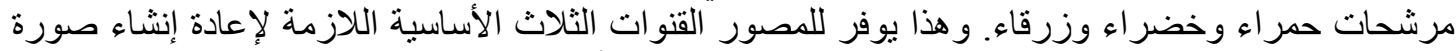

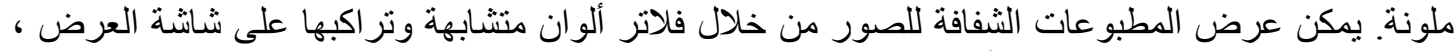

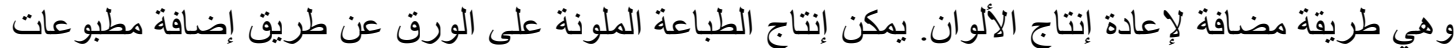

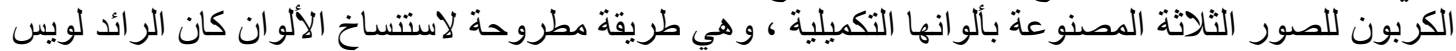

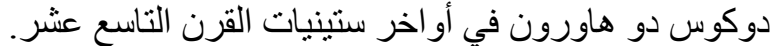

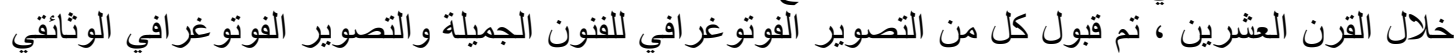

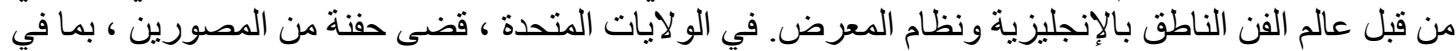

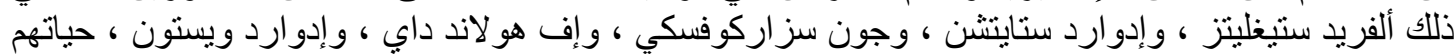

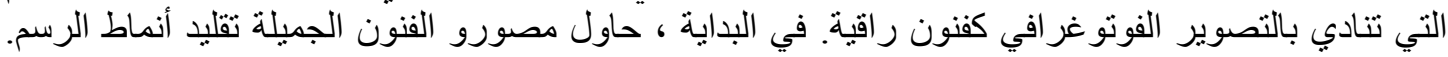

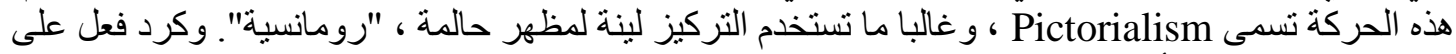

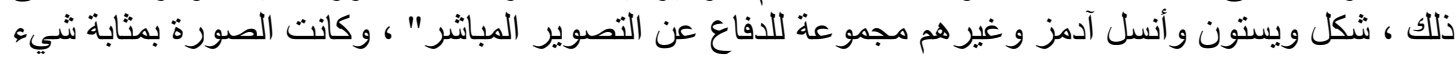

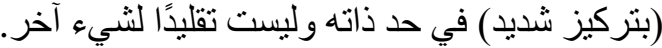

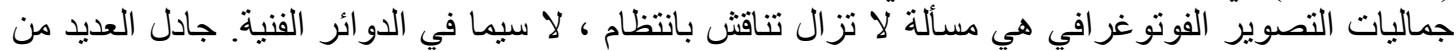

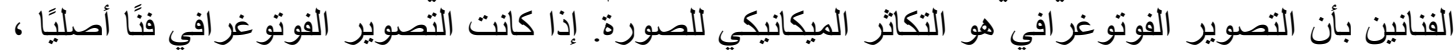

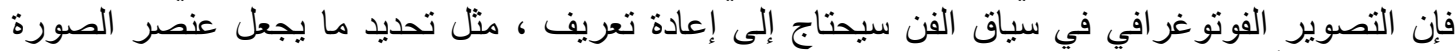

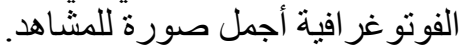
مؤشرات الإطار النظري

الماسريالية يمزج مأبرات بين السريالية التي تتبنى الأفكار والثقافات المعاصرة، وفن الميديا (وسائل الإعلام)

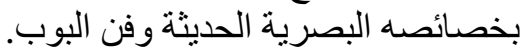

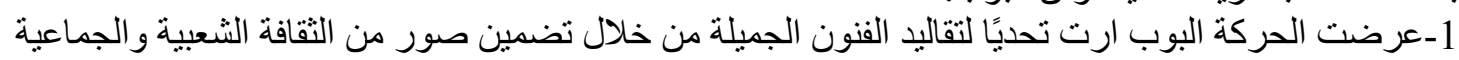

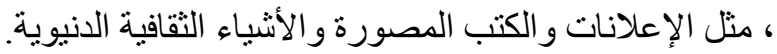

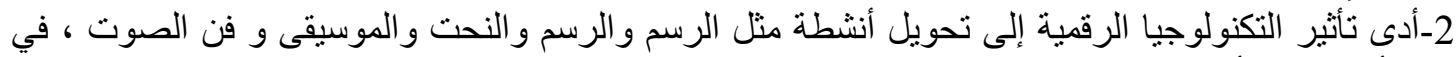

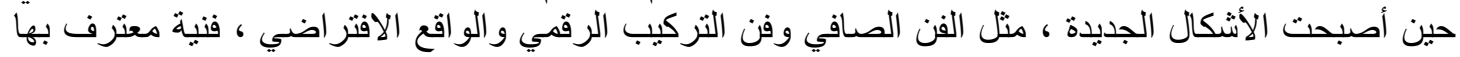

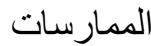
3- الفن الرقمي" هو الفن المعاصر الذي يستخدم أساليب الإنتاج الضخم أو الوسائط الرقية الفية

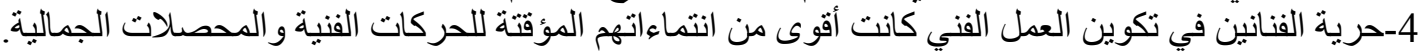

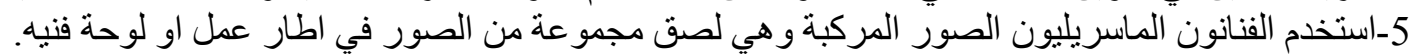

\section{الفصل الثالث}

$$
\text { صنمّمع البحثم البحث معظم اعمال الفنان سيروان بار ان المنجزة }
$$

اختارت الباحثنة ثلاثة اعمال(رسم ونحت) تغطي المساحة الماسريالية التي نفذ بها اعماله.

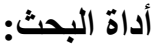

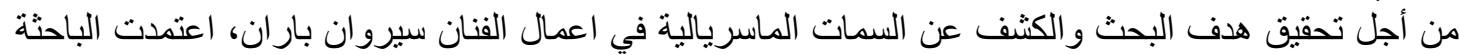

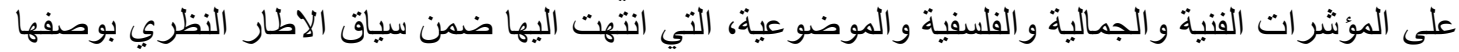

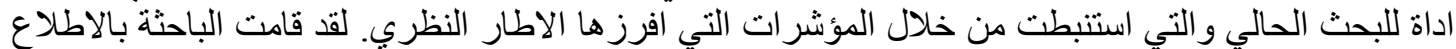

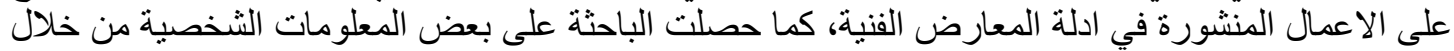

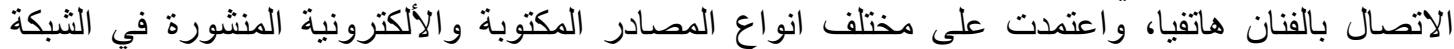
العنكبوتية لجمع بعض نماذج العينة.

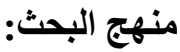
اعتمدت الباحثة المنهج الوصفي التحليلي في اتمام بحثها هذا. 


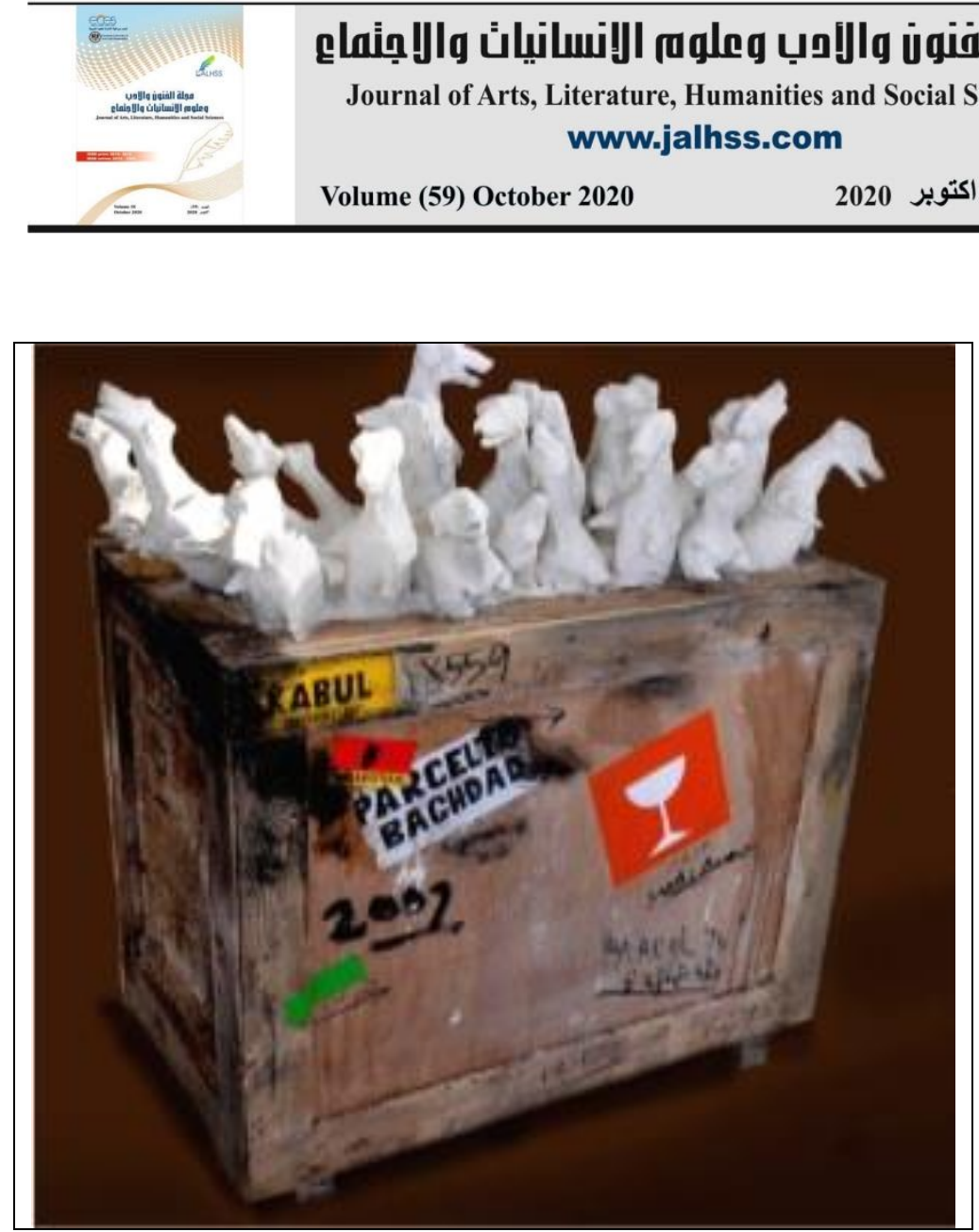

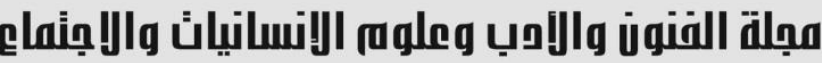
www.jalhss.com 


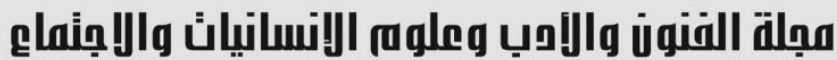

Journal of Arts, Literature, Humanities and Social Sciences
www.jalhss.com

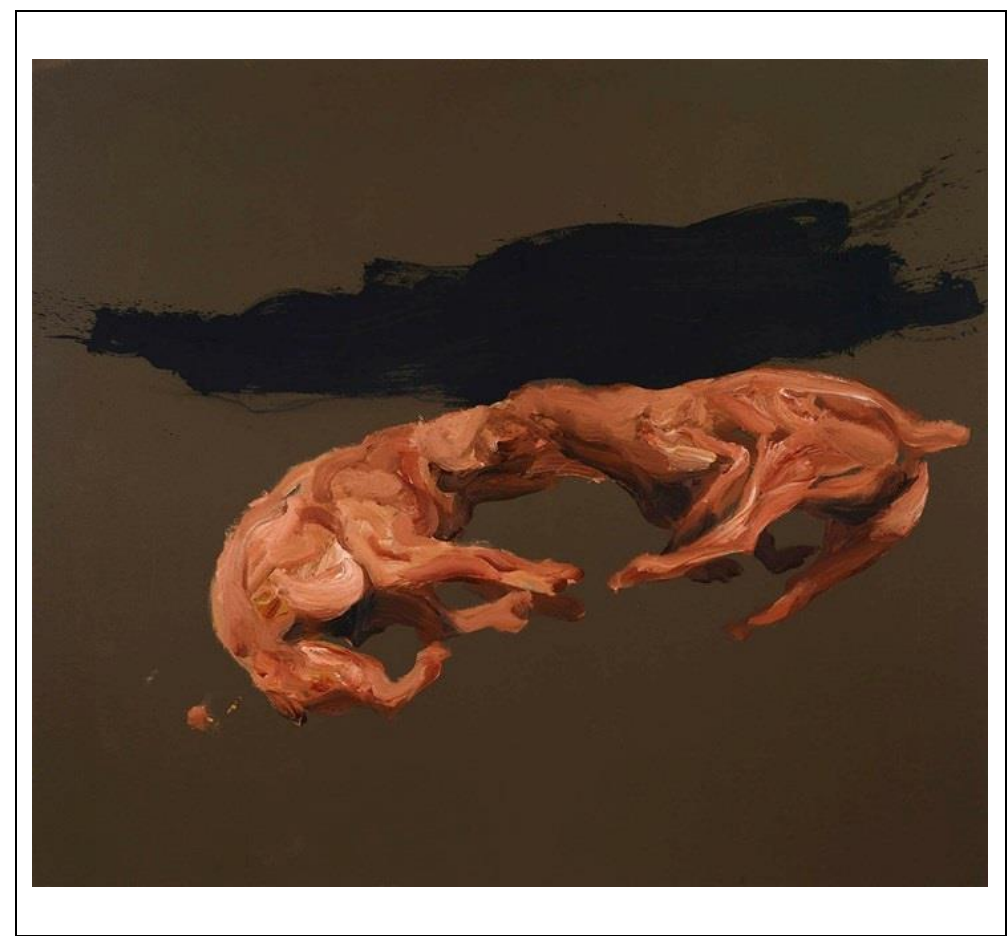

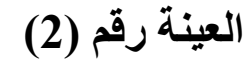

اسم العمل: صراع العزاع

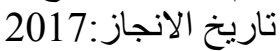

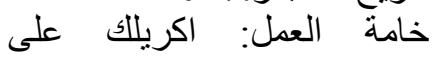

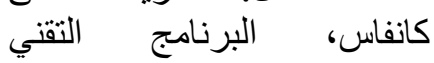
الاكتروني فوتوشوب البرن

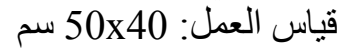
العائية: مجموعة الفنان الخاصة

الوصف البصري بظهر حالة صراع بين كلبيين بدت ملامح

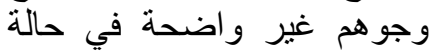
تثابك بينها فقط من الوجوه، كأن

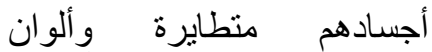
اجسادهم متتطابقة فضلاً عن الرن الجام اجسادهم كأنها محلقة في

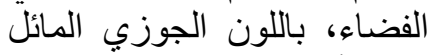

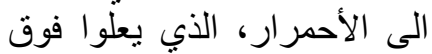
هذين الكلبين غيمة سوداء، في في لإن فضاء فارغ من التفاصيل بلون في

اما نظام التكوين فهو نظام تكوين مدور في وسط العمل، و اعتمد الفنان بناء منظومة عمله على الإنى اتجاه الاشكال

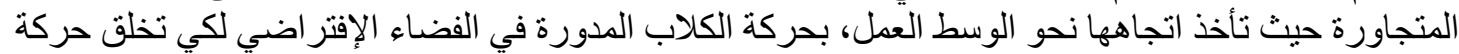

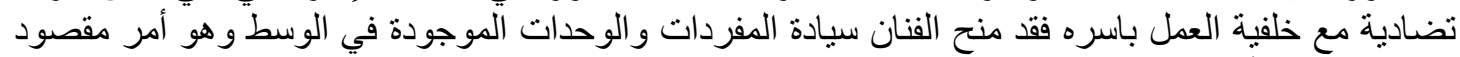

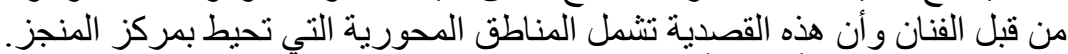

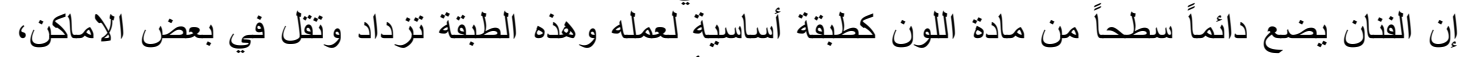

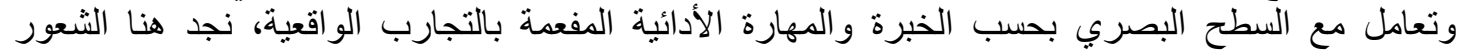

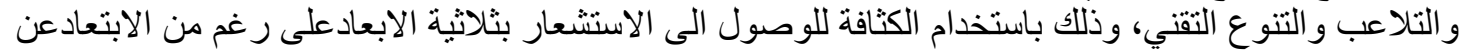

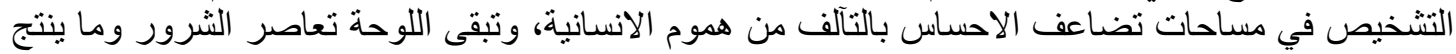
عنها من مشاهد تتجمد لها المضامين التي تنتفض مع الالوان، وتثري الخطوط بامتدادادات و اقعية تعبيرية يحاكي

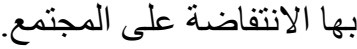
الارتداد الاجتماعي المعاصر شكل صرافئ الإنة ثقافية لاغلب أنماط الفنون المعاصرة، فالجمال والقبح كلاهما مصدر

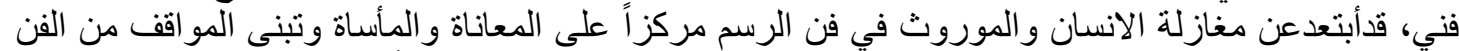

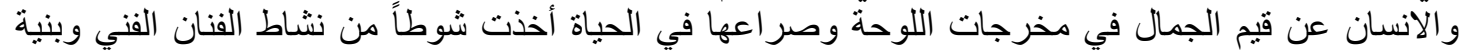

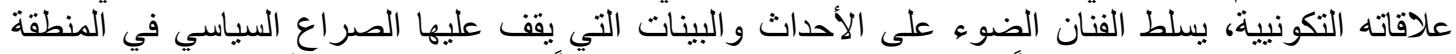

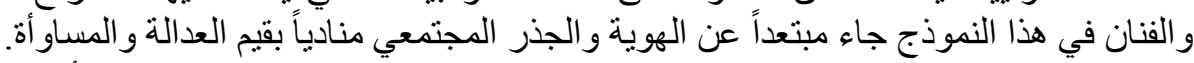

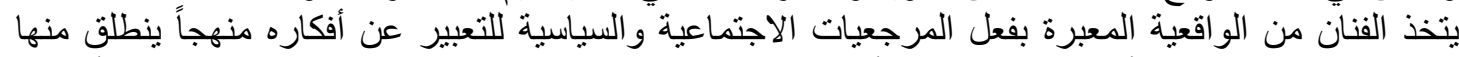

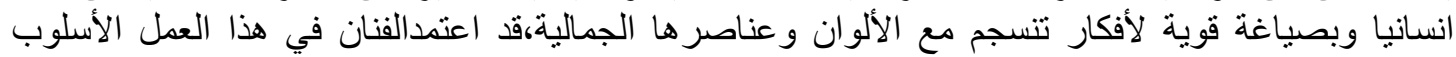

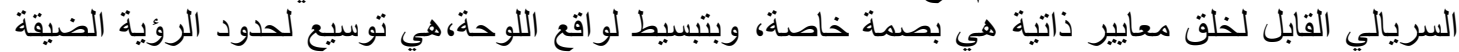

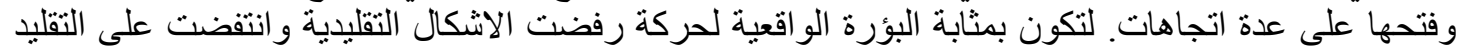

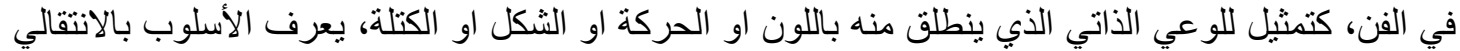

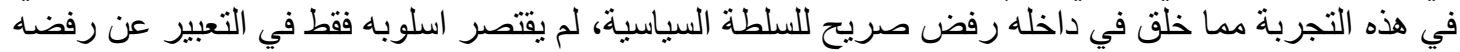

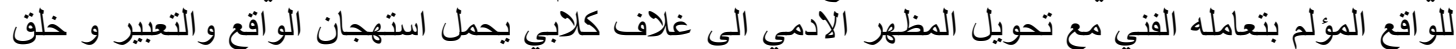

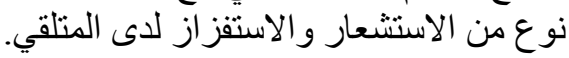




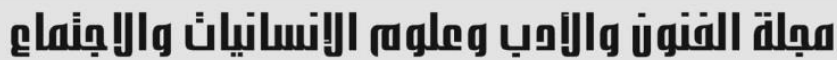

Journal of Arts, Literature, Humanities and Social Sciences
www.jalhss.com
$=$
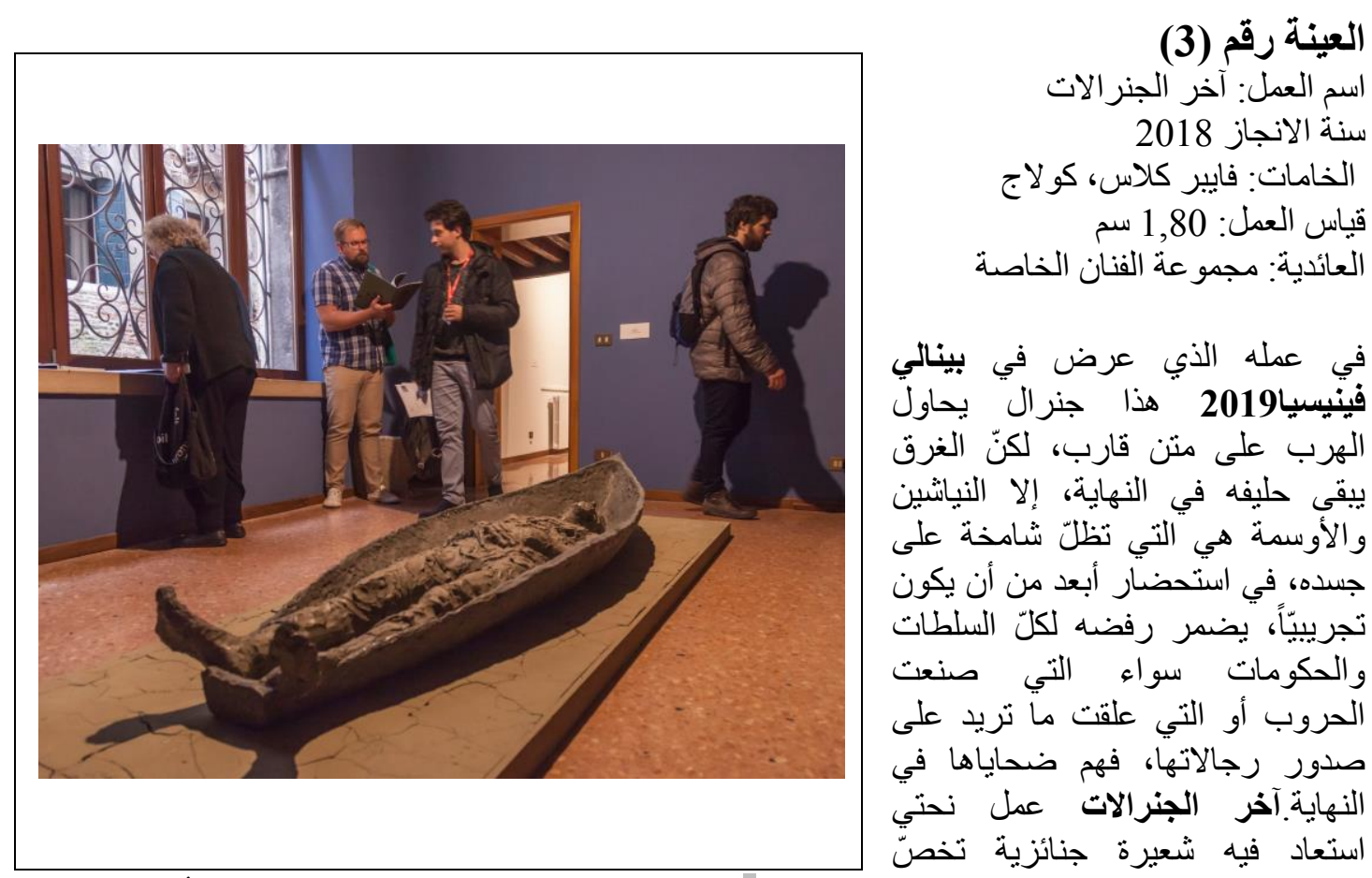

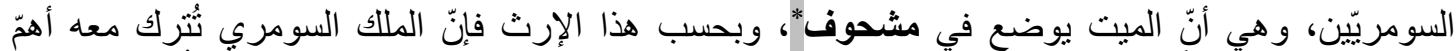

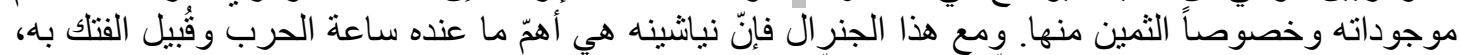

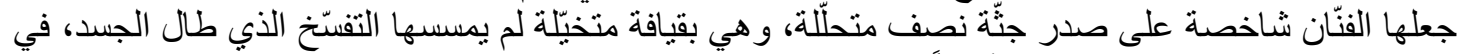

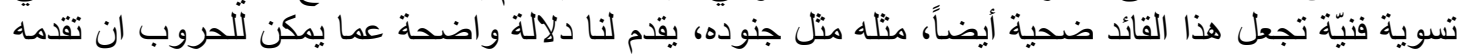

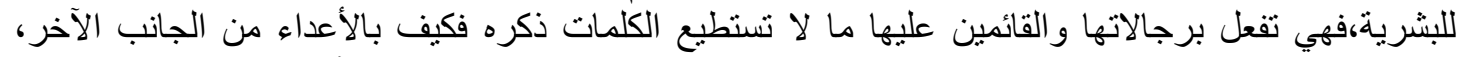

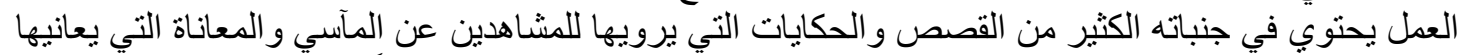

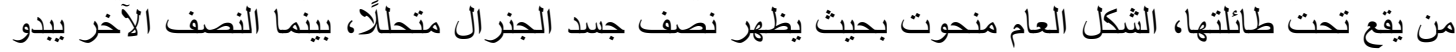

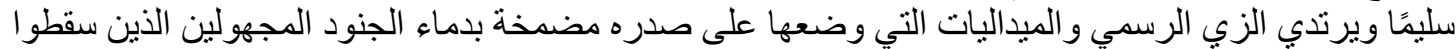
دفاعا عن الوطن، ولكن المجد كل المجد يستحوذ عليه كبار القادة سو اءأ كانو ا منتصرين او الئهي مهزومين.

في تعبير سريالي يأخذ معناه من التراث الحضاري القديم لو ادي الر افدين فان الجنر ال يبحر بقاربه في آخر رحلة يقوم بها الى العالم الأسفل عالم الاموات و هو التر ات بكامل قيافته وزينته.

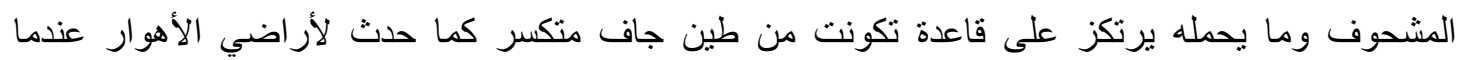

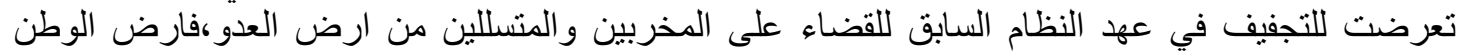

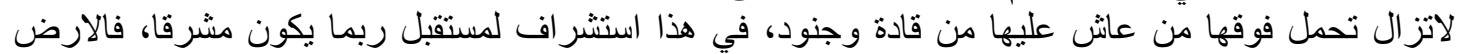

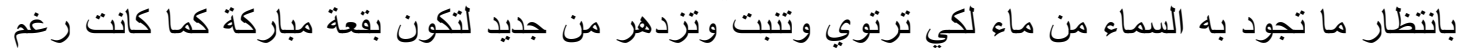

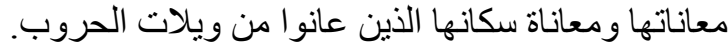




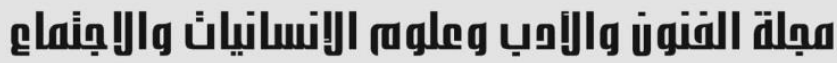

Journal of Arts, Literature, Humanities and Social Sciences

www.jalhss.com

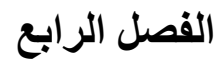

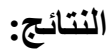

1. اعتماد الفنان على اشكال من العالم الو اقعي و اضافه بتقنيات و مدمجات فنيه مختلفه. 2.

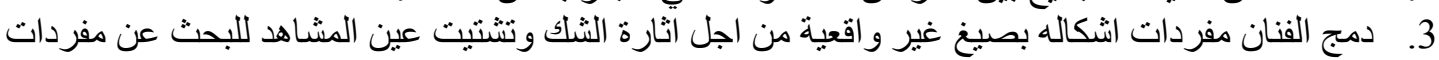
ودلالات مغايرة عن الو اقع.

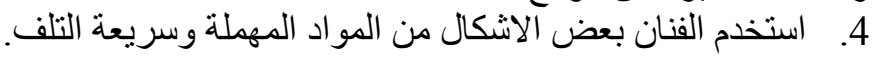

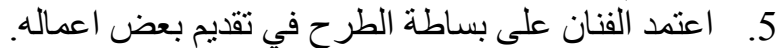

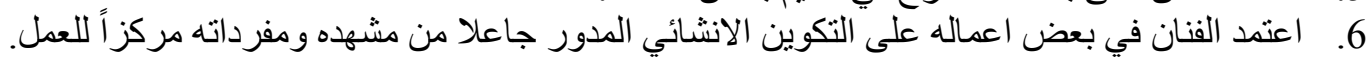

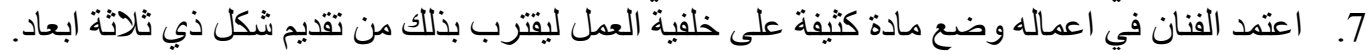

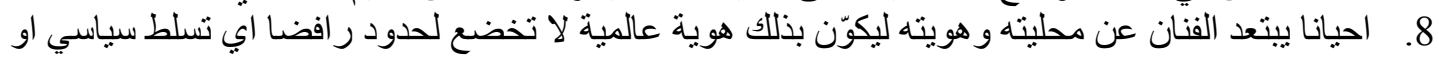

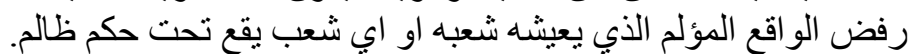

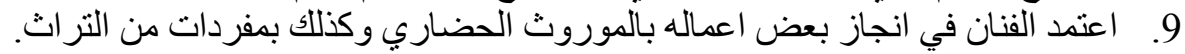

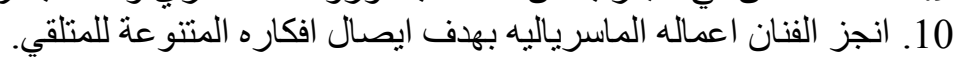

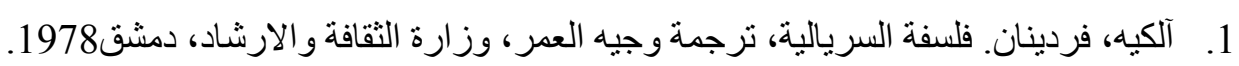

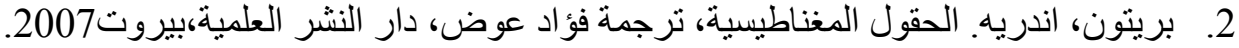

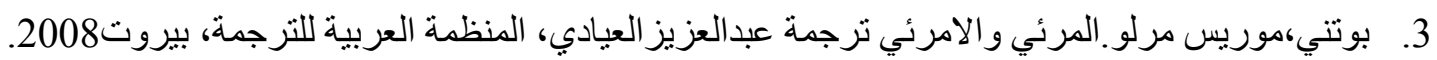

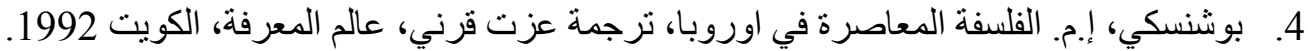

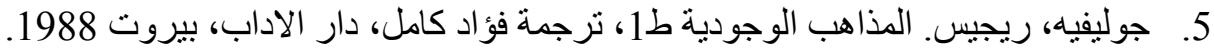

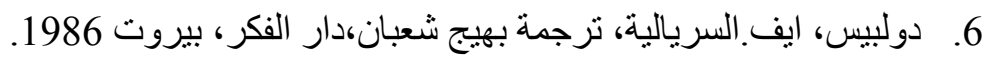
7.

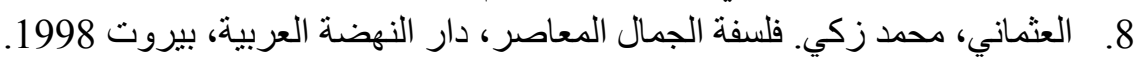

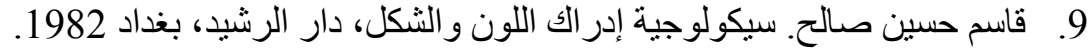

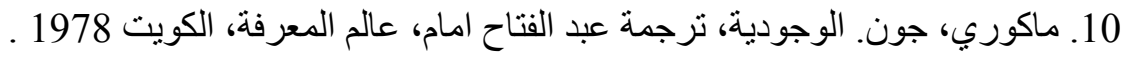

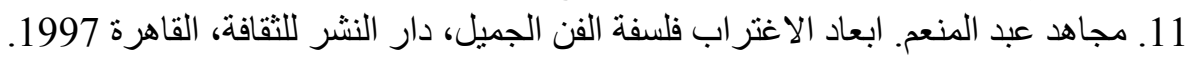

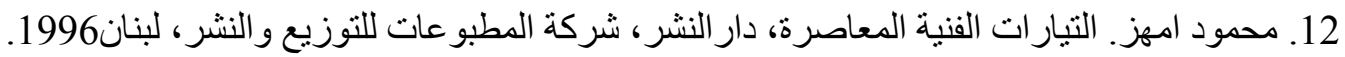

13. مصطفى، عبده. فلسفة الجمال ودور العقل في الابداع الفني،دار مدبولي، القاهرة 1999. 


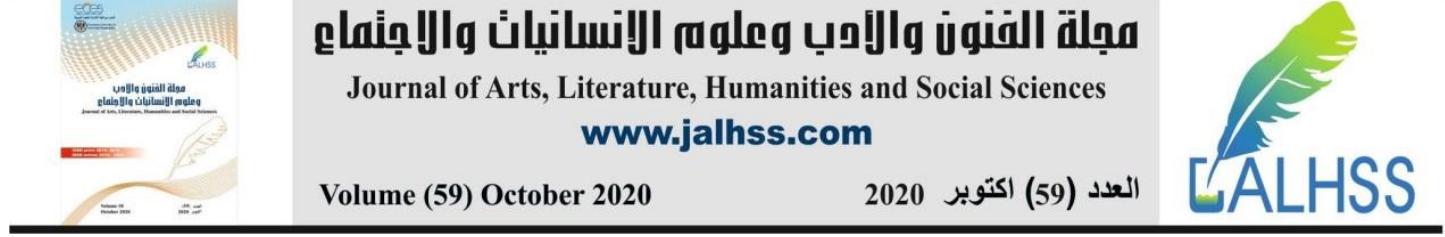

\section{References}

1. Alkeye, Ferdinand. The Philosophy of Surrealism, translated by Wajih AlOmar, Ministry of Culture and Guidance, Damascus 1978.

2. Britton, Andre. Magnetic Fields, translated by Fouad Awad, Scientific Publishing House, Beirut 2007.

3. Putney, Maurice Merlow, The Visible and the Visible, translated by Abdulaziz Al-Ayadi, Arab Organization for Translation, Beirut 2008.

4. Bushinsky, EM. Contemporary Philosophy in Europe, translated by Izzat Qarni, The World of Knowledge, Kuwait 1992.

5. Julivier, Regis. Existential Schools, First Edition, translated by Fouad Kamel, Dar Al-Adab, Beirut, 1988.

6. Dolbis, Eve. The Surrealism, translated by Bahij Shaban, Dar Al Fikr, Beirut 1986.

7. Shaker Abdel-Hamid. The process in the art of photography, the science of knowledge, Kuwait 1987.

8. Al-Othmani, Muhammad Zaki. The Philosophy of Contemporary Beauty, Arab Renaissance House, Beirut 1998.

9. Qasim Hussein Saleh. The Psychology of Perception of Color and Form, Dar Al-Rasheed, Baghdad 1982.

10. McCurry, John. Existentialism, translated by Abd al-Fattah Imam, The World of Knowledge, Kuwait 1978.

11. Mujahid Abdel Moneim. Dimensions of Alienation, Philosophy of Beautiful Art, Publishing House for Culture, Cairo 1997.

12. Mahmoud Amhaz. Contemporary Artistic Currents, Publishing House, The Prints Company for Distribution and Publishing, Lebanon 1996.

13. Mustafa Abdo. The philosophy of beauty and the role of reason in artistic creativity, Dar Madbouly, Cairo 1999.

\section{Theses:}

14. Firas Mahmoud Hassan, Psychological Dimensions in Modern Expressive Painting, Master Thesis, College of Arts, Babylon 2007. 